\title{
Invited review: A commentary on predictive cheese yield formulas ${ }^{1}$
}

\author{
D. B. Emmons ${ }^{2,3,4}$ and H. W. Modler ${ }^{4,5}$ \\ Guelph Food Research Centre, Research Branch, Agriculture and Agri-Food Canada, Ottawa, ON, Canada N1G 5C9
}

\begin{abstract}
Predictive cheese yield formulas have evolved from one based only on casein and fat in 1895. Refinements have included moisture and salt in cheese and whey solids as separate factors, paracasein instead of casein, and exclusion of whey solids from moisture associated with cheese protein. The General, Barbano, and Van Slyke formulas were tested critically using yield and composition of milk, whey, and cheese from 22 vats of Cheddar cheese. The General formula is based on the sum of cheese components: fat, protein, moisture, salt, whey solids free of fat and protein, as well as milk salts associated with paracasein. The testing yielded unexpected revelations. It was startling that the sum of components in cheese was $<100 \%$; the mean was $99.51 \%$ $(\mathrm{N} \times 6.31)$. The mean predicted yield was only $99.17 \%$ as a percentage of actual yields (PY\%AY); PY\%AY is a useful term for comparisons of yields among vats. The PY\%AY correlated positively with the sum of components (SofC) in cheese. The apparent low estimation of SofC led to the idea of adjusting upwards, for each vat, the 5 measured components in the formula by the observed SofC, as a fraction. The mean of the adjusted predicted yields as percentages of actual yields was 99.99\%. The adjusted forms of the General, Barbano, and Van Slyke formulas gave predicted yields equal to the actual yields. It was apparent that unadjusted yield formulas did not accurately predict yield; however, unadjusted PY\%AY can be useful as a control tool for analyses of cheese and milk. It was unexpected that total milk protein in the adjusted General formula gave the same predicted yields as casein and paracasein, indicating that casein or paracasein may not always
\end{abstract}

Received March 14, 2010.

Accepted July 16, 2010.

${ }^{1}$ Based on ADSA Pioneer Paper "A Century of Predictive Cheese Yield Formulas" presented July 14, 2009, at the Annual Meeting of the American Dairy Science Association, Montreal, QC, Canada.

${ }^{2}$ Corresponding author: dbemmons@sympatico.ca

${ }^{3}$ Retired; present address: 657 Westminster Ave., Ottawa, ON, K2A 2V7, Canada.

${ }^{4}$ Formerly the Centre for Food and Animal Research, Research Branch, Agriculture and Agri-Food Canada.

${ }^{5}$ Retired; present address: 1253 River Road, Kemptville, ON, K0G 1J0, Canada. be necessary for successful yield prediction. The use of constants for recovery of fat and protein in the adjusted General formula gave adjusted predicted yields equal to actual yields, indicating that analyses of cheese for protein and fat may not always be necessary for yield prediction. Composition of cheese was estimated using a predictive formula; actual yield was needed for estimation of composition. Adjusted formulas are recommended for estimating target yields and cheese yield efficiency. Constants for solute exclusion, proteinassociated milk salts, and whey solids could be used and reduced the complexity of the General formula. Normalization of fat recovery increased variability of predicted yields.

Key words: cheese, yield, prediction, formula

\section{INTRODUCTION}

This review will deal with 3 main areas: the applications for cheese yield formulas, a brief history of the development of the formulas, and experiences with the General and Barbano predictive yield formulas.

\section{Uses for Formulas}

Formulas are used to predict yield in a number of ways. This paper shows, for example, that they can likely be used to predict yields from a new milk formulation or for cheeses of different compositions. And one can likely use them to compare predicted and actual yields as a control tool to assess the measuring systems for accuracy of cheese and milk analyses, for accuracy of weights and measurements, and for accuracy of sampling. The formula does not identify the problem, but can identify that a problem exists. A formula can be used to adjust an observed yield to a yield of constant composition, particularly in research experiments. A formula can also be used to assess cheese yield efficiency by comparing an observed yield to an adjusted predicted yield of target composition.

\section{Early Formulas}

The first predictive yield formula of which we are aware was a simple one: 


$$
\text { Yield }=1.1 \times \% \text { fat }+2.5 \times \% \text { cas; }
$$

it used only casein (cas) and fat and appeared in a report by Babcock (1895).

The second appeared in a textbook on cheesemaking by Van Slyke and Publow (1910):

$$
\begin{aligned}
\text { Yield } & =(0.93 \times \% \text { fat }+\% \text { cas }-0.1) \\
& \times 1.09 /[(100-\% \mathrm{M}) / 100] .
\end{aligned}
$$

The formula introduced moisture $(\mathbf{M})$ as a separate factor and had a constant of 1.09, the 0.09 of which represented cheese salt (SC), milk salts, and carbohydrates in the cheese. This formula appeared in subsequent issues of the book by Van Slyke and Price (1949) and has been widely known as the Van Slyke or the Van Slyke and Price formula.

The Van Slyke and Price formula was developed for Cheddar cheese. Ernstrom et al. (1981) modified the Cheddar formula for part-skim, low-moisture Mozzarella cheese:

$$
\begin{aligned}
\text { Yield }= & (0.86 \times \% \text { fat }+\% \text { cas }-0.36) \\
& \times 1.22 /(1-\mathrm{M} \% / 100),
\end{aligned}
$$

which differed in having a larger constant of 1.22 in the numerator and 0.36 replaced 0.1. Barbano (1984) published a different formula for Mozzarella:

$$
\begin{aligned}
\text { Yield }= & (0.85 \times \% \text { fat }+\% \text { cas }-0.1) \\
& \times 1.13 /(1-\mathrm{M} \% / 100) .
\end{aligned}
$$

Posthumus et al. (1964) published a yield formula, or rather a series of formulas that together gave the yield. Their formula differed in a number of ways from that of Van Slyke and Price (1949). It introduced SC, whey solids (WS), and something other than cas as separate factors into the equation. A few of the differences were

1. Calculation of the amount of WS in cheese as the amount of $\mathrm{M} \times \mathrm{WS} /(1-\mathrm{WS})$.

2. Introduction of the idea that "some water in cheese is colloidally bound" to cheese protein, excluding WS; this is now known as solute exclusion.

3. Instead of cas in the yield formula, a factor called alpha was used; when multiplied by protein in milk, it represented protein going from milk to cheese, as well as calcium phosphate associated with the paracasein (pc). The value of alpha varied seasonally from 0.795 to 0.813 and repre- sented the means of 20 factories over 3 yr. The alpha factor seemed to have been predictable and is a means to avoid analysis of cas or pc in milk.

A report by Lolkema (1994) outlined in detail how cheese yield was used as an instrument for process control in plants making Gouda cheese in the province of Friesland. It was in these plants that the author first saw such control and was convinced that yield formulas could have a real place in cheese factories. Milk for the next day's cheesemaking was analyzed for standardization. In the plant, it was surprising to see very few personnel, but a lot of mechanization. Cheeses coming from the presses were individually weighed automatically and recorded in computers. By the end of the first 10 vats, computations were being made to see if the correct amount of cheese was being produced. If the yields were higher or lower, the cheesemaker could see at a glance whether modifications in the making procedures were necessary to increase or decrease the $\mathrm{M}$ in the cheese for the other 30 vats that day.

A detailed, well-documented treatise by van den Berg et al. (1996) dealt with many facets of mass transfer processes involved in making Gouda cheese in relation to cas and yield. A procedure for measuring pc in milk was described using a calibrated infrared instrument, first described by Karman et al. (1987). This was used in cheese plants for the "widespread practice (in the Netherlands) of filling vats with a constant amount of paracasein." Combined with standardization of the ratio of pc to fat in milk, it is easy to use yield of cheese as a measure of M. Van de Berg et al. (1996) also indicated that "almost all processing plants use a monitoring control loop with the results of moisture determinations in cheese... superimposed on direct process control loops;" control charts were also used.

Many other papers deal with cheese yields and formulas. One that should be mentioned is that of Maubois and Mocquot (1971), which recognized solute exclusion by cheese protein. Several papers appeared in publications of the International Dairy Federation (1993, 1994, 2000). Attention should also be given to Barbano (1994), which describes a spreadsheet system for evaluation and improvement of cheese yield performance that is pragmatic and relatively simple.

\section{Integration of Yield Formulas with Cheesemaking}

Three references dealt with commercial applications. Posthumus et al. (1964) compared actual and predicted yields of every vat. Lolkema (1994) controlled M content by measuring yield of cheese from standardized milk and adjusting the making procedure accordingly. 
Similarly, van den Berg et al. (1996) controlled M by measuring yield from vats containing constant amounts of pc in standardized milk. In all cases, cheese factories were designed in such a way that vital measurements could be made.

\section{EXPERIENCES WITH FORMULAS}

The following is a commentary or critical examination of yield formulas using the General and Barbano formulas and, in one instance, the Van Slyke formula, as examples. In this examination, insights evolved that were new to the authors regarding those formulas and their possible applications.

The following review and commentary used data from 1 large experiment making 22 vats of cheese in which yield and many components were measured. The composition of milk, whey, and cheese was used by Emmons et al. (2003). The carbohydrates and associated components were reported by Mullin and Emmons (1997). The milk salts associated with casein were analyzed by Ihnat (personal communication). The basic data from that cheesemaking experiment were used for various calculations (see later) for this review, occasionally described as being from 22 vats of cheese.

\section{General Formula}

The General formula is a theoretical formula based on the sum of the quantities of components in cheese: fat, plus protein, plus milk salts (ms) associated with the pc (calcium, phosphate, magnesium, and citrate), minus a factor (seWS) for WS not included because of solute exclusion, plus SC, plus M, plus WS (as if there was no solute exclusion).

The General formula for predicting yield $(\mathbf{Y})$ of cheese (ch), its theoretical basis, its rearrangement, and its working form are as follows. On a theoretical basis,

$$
\begin{aligned}
\mathrm{Y} & =\text { sum of cheese components } \\
& =\mathrm{F}+\mathrm{P}+\mathrm{ms}-\text { seWS }+\mathrm{Y} \times \mathrm{SC}+\mathrm{Y} \times \mathrm{M}+\mathrm{Y} \times \mathrm{WS} .
\end{aligned}
$$

This can be rearranged as

$$
\mathrm{Y}=\frac{\mathrm{F}+\mathrm{P}+\mathrm{ms}-\mathrm{seWS}}{(1-\mathrm{SC}-\mathrm{M}-\mathrm{WS})} .
$$

In its working form:

$$
\begin{aligned}
\mathrm{Y} & =\frac{\mathrm{FM} \times \mathrm{Kf}+\mathrm{pc} \times \mathrm{KpcPr} \times \mathrm{Kms}-h \times \mathrm{pc} \times \mathrm{KpcPr} \times \mathrm{ffpfW} /(1-\mathrm{ffpfWS})}{1-\mathrm{SC}-\mathrm{M}-\mathrm{M} \times \mathrm{ffpfWS} /(1-\mathrm{ffpfWS})} \\
& =\frac{\mathrm{FM} \times \mathrm{Kf}+\mathrm{pc} \times \mathrm{KpcPr} \times[\mathrm{Kms}-h \times \mathrm{ffpfWS} /(1-\mathrm{ffpfWS})]}{1-\mathrm{SC}-\mathrm{M} \times[1+\mathrm{ffpfWS} /(1-\mathrm{ffpfWS})]},
\end{aligned}
$$

where $\mathrm{Y}=$ yield of $\mathrm{ch}, \mathrm{kg} / 100 \mathrm{~kg}$ of milk; $\mathrm{F}=$ fat in cheese $=\mathrm{FM} \times \mathrm{Kf} ; \mathrm{FM}=\%$ fat in milk; $\mathrm{Kf}=$ recovery of milk fat as ch $=$ weight $\mathrm{ch} \times$ fat ch/weight milk $\times$ $\mathrm{FM} ; \mathrm{pc}=\%$ paracasein in milk; $\mathrm{P}=$ protein in cheese $=\mathrm{pc} \times \mathrm{KpcPr} ; \mathrm{KpcPr}=$ recovery of milk $\mathrm{pc}$ as $\mathrm{ch}$ protein $=$ weight $\mathrm{ch} \times$ protein $\mathrm{ch} /$ weight milk $\times \mathrm{pc} ; \mathrm{ms}$ $=\mathrm{Ca}, \mathrm{Mg}$, inorganic phosphate, and citrate associated with protein in cheese; $\mathrm{Kms}=1+$ ratio of ms to protein in ch; $\mathrm{SC}=\%$ salt in $\mathrm{ch} / 100 ; \mathrm{M}=\%$ moisture in $\mathrm{ch} / 100 ; \mathrm{WS}=\mathrm{M} \times \mathrm{ffpfWS} /(1-$ ffpfWS $) ; \mathrm{ffpfWS}=\%$ fat-free, protein-free solids in whey $/ 100 ;$ seWS $=$ ffpfWS not in solute-excluding water associated with protein in $\mathrm{ch}=h \times \mathrm{pc} \times \mathrm{KpcPr} \times \mathrm{ffpfWS} /(1-\mathrm{ffpfWS}) ; h=$ solute-exclusion factor (sef) for ffpfWS with ch protein. Whey solids in the theoretical formula is the amount of ffpfWS in the cheese, assuming no solute exclusion in cheese; seWS represents the amount of ffpfWS not there because of solute exclusion by the cheese protein; the seWS is quantified by multiplying by the amount of protein in the cheese and by $h$ and thus is in that part of the formula. Salt, moisture, and WS are represented as fractions or percentages of cheese; multiplication by Y quantifies their amounts in cheese $/ 100 \mathrm{~kg}$ of milk.

The rearranged formula is also shown, giving the latest version (working formula). Earlier versions were by Emmons et al. (1990, 1993).

Protein in cheese is pc in milk $\times$ a recovery factor (KpcPr), in the same manner as the recovery of milk fat as cheese fat (Kf). A spreadsheet was used to calculate the predicted yield: the factors $\mathrm{KpcPr}$ and $\mathrm{Kf}$ were calculated in the spreadsheet. Fat-free, protein-free whey solids (ffpfWS) are used; transfers of whey fat and protein are in other parts of the formula. The factor (Kms) equals 1.0 plus the ratio of $\mathrm{ms}$ to the protein in cheese; when Kms is multiplied by protein, it quantifies the ms and protein in cheese. This assumes a close relation between the amount of ms and protein in cheese. A negative factor in the numerator, seWS, accounts for the ffpfWS excluded from water associated with the pc; it is the solute-exclusion factor $(\boldsymbol{h})$ times the amount of protein in the cheese times ffpfWS/(1 - ffpfWS $)$. Total milk protein $(\mathbf{m p})$ and cas (see later) can be used as well as pc in the formula; appropriate changes are made to recovery factors for cas (KcasPr) and $\mathrm{mp}$ (KmpPr), respectively, in cheese. The denominator incorporated $\mathrm{M}, \mathrm{SC}$, and WS.

A spreadsheet was used to calculate the predicted yield and such factors as $\mathrm{Kf}$ and $\mathrm{KpcPr}$. A general spreadsheet incorporated the following: weights of milk and cheese; fat, total protein, cas, and/or pc in milk; total solids, fat, protein, and ffpfWS in whey; M, total protein, and $\mathrm{SC}$ in cheese; $h, \mathrm{Kms}, \mathrm{KpcPr}$, and $\mathrm{Kf}$; $\mathrm{Kf}$ and $\mathrm{KpcPr}$ were calculated as described above. As will be seen later, the spreadsheet contained a cell for 
calculation of yield using the formula and cells for calculations of ms and ffpfWS in the cheese, of sum of components (SofC), and of adjusted yield.

\section{Solute Exclusion}

Solutes are excluded from water associated with proteins (van Boekel, 1994, among many); that water has also been known as bound water. Solute exclusion of lactose and other molecules by milk proteins had been known for some decades but its application in a cheese yield formula has been relatively new. The $h$, as used in the General formula, can be defined as the proportion or ratio of the weight of excluding water to the weight of the cas or pc, or of the protein in cheese. Maubois and Mocquot (1971) used a factor of 0.5, which approximates that in the literature for lactose; that is, lactose was excluded from 0.5 grams of water for every gram of protein in cheese.

\section{Barbano Formula} low:

The Barbano formula (Barbano, 1996) is shown be-

$$
\text { Yield }=\frac{(\mathrm{A}+\mathrm{B}+\mathrm{C})}{1-[(\text { cheese } \mathrm{M}+\text { salt }) / 100]},
$$

where $\mathrm{A}=$ milk fat recovered $=\mathrm{Kf} \times \%$ fat in milk; $\mathrm{B}=$ milk cas recovered $+\mathrm{CaPO}_{4}=(\%$ cas in milk - 0.1) $\times\left(\mathrm{CaPO}_{4}\right.$ retention $) ; \mathrm{C}=$ other milk solids recovered (other than fat, cas, salt, $\mathrm{CaPO}_{4}$ ); that is, fat-free whey solids $=(\{[(\mathrm{A}+\mathrm{B}) /(1-\mathrm{M} / 100)-(\mathrm{A}+$ B) $] \times(\%$ separated whey solids $/ 100)\} \times$ sef $)$, and $\mathrm{M}$ $=\%$ cheese moisture; $\mathrm{CaPO}_{4}$ retention $=1.09$; sef $=$ solute exclusion factor; and $\mathrm{Kf}=$ recovery of milk fat as cheese fat, as a fraction. The first part of $\mathrm{C}$ is a novel method of calculating the amount or weight of water in the cheese. We presume that multiplying that by the percentage fat-free whey solids (ffWS) is intended to give the amount of ffWS; however, as indicated earlier, it is suggested that it should be further divided by $1-$ \%ffWS/100. This component is then multiplied by sef. First, this sef should not be confused with the $h$ used in the General formula - it is not the same; second, this sef might be called a ffWS recovery factor; and third, these comments may make very little difference in the end result, because this sef is calculated using the shown formula and various known values. Thus, making the change would likely result in a lower value for sef but the same estimated quantity of ffWS. In summary, this formula has been used with much success by Barbano and colleagues in their many papers on yield.

\section{Cheese and Cheesemaking}

The General and Barbano formulas were tested on cheese and cheesemaking in an experiment for another purpose (Emmons et al., 1997, 2003). The experiment comprised 11 lots of milk from one herd, from May to December, making 2 vats of cheese per lot. The 22 vats of cheese were treated as separate entities because interest was primarily in how the formulas predicted yield. Cheesemaking was in vats of $225-\mathrm{kg}$ capacity containing 210 to $215 \mathrm{~kg}$ of milk. Milk was previously heated to $60^{\circ} \mathrm{C}$ for $30 \mathrm{~min}$; the temperature was lower than that used for pasteurization to minimize denaturation of whey proteins. Milk, whey, and cheese were weighed on a platform scale with $32-\mathrm{kg}$ capacity and with 1 - and $0.1-\mathrm{g}$ graduations. Homofermentative starter concentrates were used to circumvent the problems of how to include the starter milk and of fermentations to carbon dioxide. Milk, whey, and cheese were analyzed as described by Emmons et al. (2003), and the experiment included a relatively large number of subsamples and replicate analyses. The method of estimation of pc was also described.

The mean levels in 11 vats of milk for fat, total protein $(\mathrm{N} \times 6.38)$, casein $(\mathrm{N} \times 6.38)$, pc $(\mathrm{N} \times 6.38)$, and $\mathrm{pc}(\mathrm{N} \times 6.31)$ were $3.667,3.044,2.363,2.286$, and $2.261 \%$, respectively; standard deviations (SD) among the 11 lots were $0.114,0.056,0.045,0.042$, and $0.041 \%$, respectively. The mean levels in 22 vats of whey for total solids, fat, protein $(\mathrm{N} \times 6.38)$, ffWS, and ffpfWS were $6.599,0.082,0.832,5.516$, and $5.684 \%$, respectively; SD among the 22 vats were $0.08,0.062,0.018$, 0.043 , and $0.038 \%$, respectively. The mean levels in 22 vats of cheese for $\mathrm{M}$, fat, $\mathrm{SC}$, total protein $(\mathrm{N} \times 6.38)$, and total protein $(\mathrm{N} \times 6.31)$ were $35.19,35.40,1.46$, 24.25 , and $23.98 \%$, respectively; SD among the 22 vats were $0.42,0.71,0.06,0.55$, and $0.54 \%$, respectively.

\section{Solute Exclusion and Fat-Free Protein-Free Whey Solids}

With respect to solute exclusion, small amounts of lactose, galactose, formic acid, and acetic acid were present in the cheese at 1 wk of age: 0.03, 0.04, 0.05, and $0.02 \%$, respectively. Lactic was the major acid at $1.19 \%$, giving a mean total of $1.32 \%$ carbohydrate in the 22 vats of cheese respectively; the SD was $0.05 \%$. High performance liquid chromatography was used for analysis of these sugars and organic acids as well as citric acid (Mullin and Emmons, 1997). These levels were similar to those in other studies.

Solute exclusion of ffpfWS by total protein in cheese was estimated as follows. Carbohydrate comprised a mean $86 \%$ of the ffpfWS in whey. It was not known 
what the $h$ values were for the $14 \%$ of remaining ffpfWS so it was assumed that their $h$ values were the same as that of the carbohydrates; this gave an estimate of the ffpfWS in cheese. The proportional amount of water associated with the ffpfWS in cheese was calculated in each vat using their ratio in whey; the difference from the total $\mathrm{M}$ in the cheese was the solute-excluded or ffpfWS-excluded M, and the $h$ value was the ratio of that $\mathrm{M}$ to the total cheese protein. The mean of $h$ values in the 22 vats of cheese was 0.411 assuming an $\mathrm{N}$-conversion factor of 6.31 ; the $h$ decreased to 0.407 for an N-conversion factor of 6.38 ( $\mathrm{SD}=0.029$ for both). The reason for the difference is that the amounts of excluded carbohydrate and excluding water were the same, but they were related to different quantities of calculated protein. It should be recognized that conversion of lactose to lactic acid and whey syneresis are concurrent processes and that the $h$ values of lactose and lactic acid are undoubtedly different; however, the majority of whey is expelled early in cheesemaking and the amount of lactose conversion is relatively small at that time. Extensive analyses throughout the cheesemaking would be required for more precise values of $h$. The mean total of ffpfWS was estimated as $1.54 \%$ (SD $=0.056 \%)$ in the cheese.

\section{Milk Salts Associated with Paracasein in Cheese}

The ms of $\mathrm{Ca}, \mathrm{Mg}$, inorganic phosphate, and citric acid, associated with the protein in cheese, comprised $40.1,1.5,48.9$, and $9.6 \%$, respectively, of a mean total of $1.935 \%(\mathrm{SD}=0.044 \%)$ in the cheese. The mean ratio of $\mathrm{ms}$ to cheese protein was 0.0807 where the $\mathrm{N}$-conversion factor was 6.31 and 0.0798 ( $\mathrm{SD}=0.0019$ for both) for an N-conversion factor of 6.38. Addition of 1 to those ratios gave the Kms in the formula. Calcium phosphate equated to a mean of $7.07 \mathrm{~g}$ per $100 \mathrm{~g}$ of protein in cheese in this review. This compared well with $7.28 \mathrm{~g}$ of calcium phosphate per $100 \mathrm{~g}$ of cas in milk as found by Trouw (Figure 6 on page 512 in van den Berg et al., 1996), and was lower than the $9.0 \mathrm{~g}$ per $100 \mathrm{~g}$ in the Barbano formula.

The $\mathrm{Ca}, \mathrm{Mg}$, and $\mathrm{P}$ were determined in the laboratories of Analytical Research Services, Land Resources Research Centre, Research Branch, Agriculture and Agri-Food Canada, Ottawa (M. Ihnat; personal communication). The $\mathrm{Ca}$ and $\mathrm{Mg}$ were determined by acid digestion-flame atomic absorption spectrometry; $\mathrm{P}$ was measured by acid digestion-light absorption spectrometry of the molybdovanado-phosphate complex. The results of analyses by these procedures of reference nonfat dry milk from the National Bureau of Standards (Gaithersburg, MD) were within specifications.
Table 1. The sum of components, actual yield (Y), predicted yield, predicted yield as a percentage of actual yield (PY\%AY), and standard deviations (SD) in 22 vats of cheese in this review

\begin{tabular}{lrl}
\hline Item & Mean & SD \\
\hline Total sum of components $^{1}(\%)$ & 99.51 & 0.12 \\
Actual yield (kg) $_{\text {Predicted yield }}^{2}(\mathrm{~kg})$ & 9.40 & 0.17 \\
PY\%AY (\%) & 9.32 & 0.17 \\
\hline
\end{tabular}

${ }^{1}$ The components in cheese that were analyzed were fat, protein $(\mathrm{N}$ $\times$ 6.31), moisture, salt, milk salts associated with cheese protein and fat-free, protein-free whey solids. The mean of the sums for the 22 vats was $99.51 \%$.

${ }^{2}$ The General formula was used to predict the yield using paracasein $(\mathrm{N} \times 6.31)$ and fat in milk, moisture, and salt in cheese, fat-free protein-free solids in whey, and measured values for solute-exclusion factor $(h)$ and the Kms factor $(1+$ ratio of milk salts $(\mathrm{ms})$ to protein in cheese) for milk salts.

The amounts of $\mathrm{Ca}, \mathrm{Mg}, \mathrm{P}$ (as $\mathrm{H}_{2} \mathrm{PO}_{4}$ ), and citric acid associated with the total protein in cheese were estimated as their levels in cheese less the amounts in the cheese moisture, assuming the same levels as in the cheese whey. Additionally, $\mathrm{P}$ in cheese protein was also subtracted from $\mathrm{P}$ in cheese and was estimated as follows: cas contained $0.86 \% \mathrm{P}$ (Table 6, Chapter 4 in Jenness and Patton, 1959); $\mathrm{P}$ was in the pc and it was $96 \%$ of cas (Emmons et al., 1990); and the ratio of total protein to pc in cheese was estimated as 1.0151 (Emmons et al., 2003), which gave an estimate of the $\mathrm{P}$ content of the cheese protein itself as $0.8825 \%$.

\section{Sum of Components in Cheese and Predicted Yield}

Table 1 shows that the mean of the sums of analyzed components was $99.51 \%$ in the 22 vats in this review. Calculations with the General formula gave a mean predicted yield as percentage of actual yield (PY\%AY) of $99.17 \%$. The SD values were such that the means were significantly different $(P<0.01)$ from $100 \%$. These low percentages were unexpected. The data in Table 1 used an N-conversion factor of 6.31; the theoretical estimation for $\mathrm{N}$ conversion for pc of 6.31 by van Boekel and Ribadeau-Dumas (1987) is compelling, yet its use contributed to a low SofC. The matter of the $\mathrm{N}$-conversion factor remains the most troubling for the authors in this review.

An N-conversion factor of 6.38 gave a mean SofC of $99.77 \%$ and a mean PY\% AY of $99.61 \%$, which were still less than 100\%. Except as noted in Figures 1, 2, and 3, subsequent calculations used $\mathrm{N} \times 6.38$, which is used almost universally elsewhere. The term PY\% AY is a good way to compare predicted yields in different vats, and it was used throughout this review. 


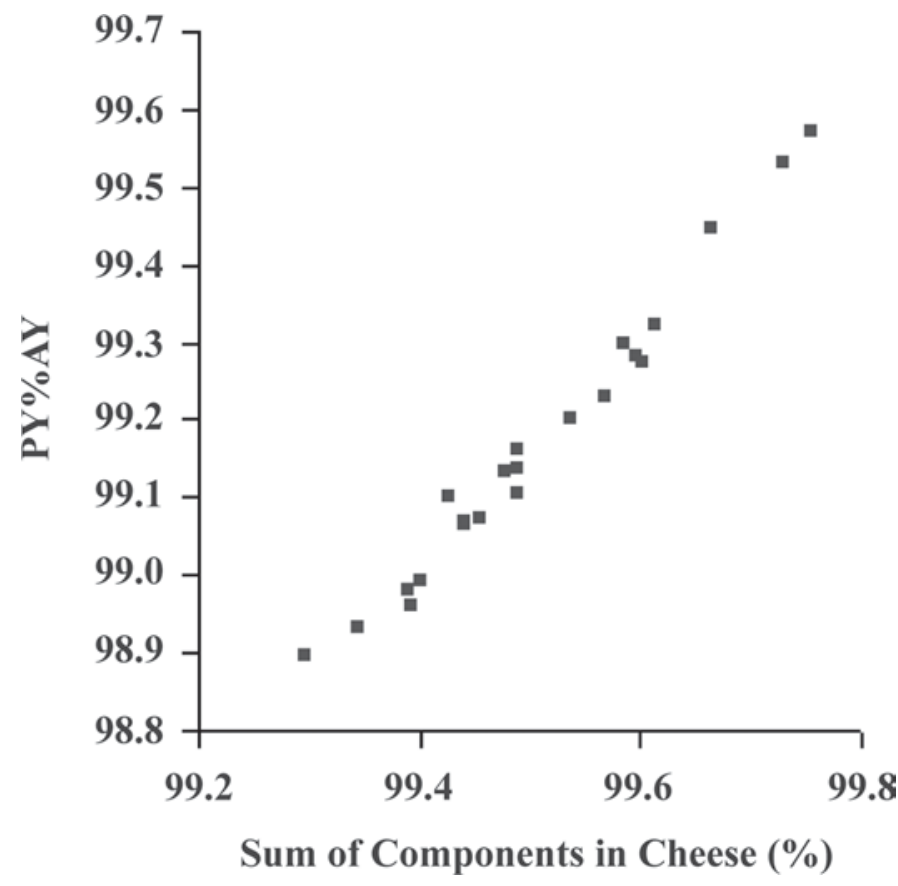

Figure 1. Relationship between the sum of components (SofC) in cheese and the predicted yield of cheese as a percentage of actual yield $(\mathrm{PY} \% \mathrm{AY})$ using paracasein $(\mathrm{N} \times 6.31)$ in the General formula. See Table 1 for an explanation of SofC and predicted yields.

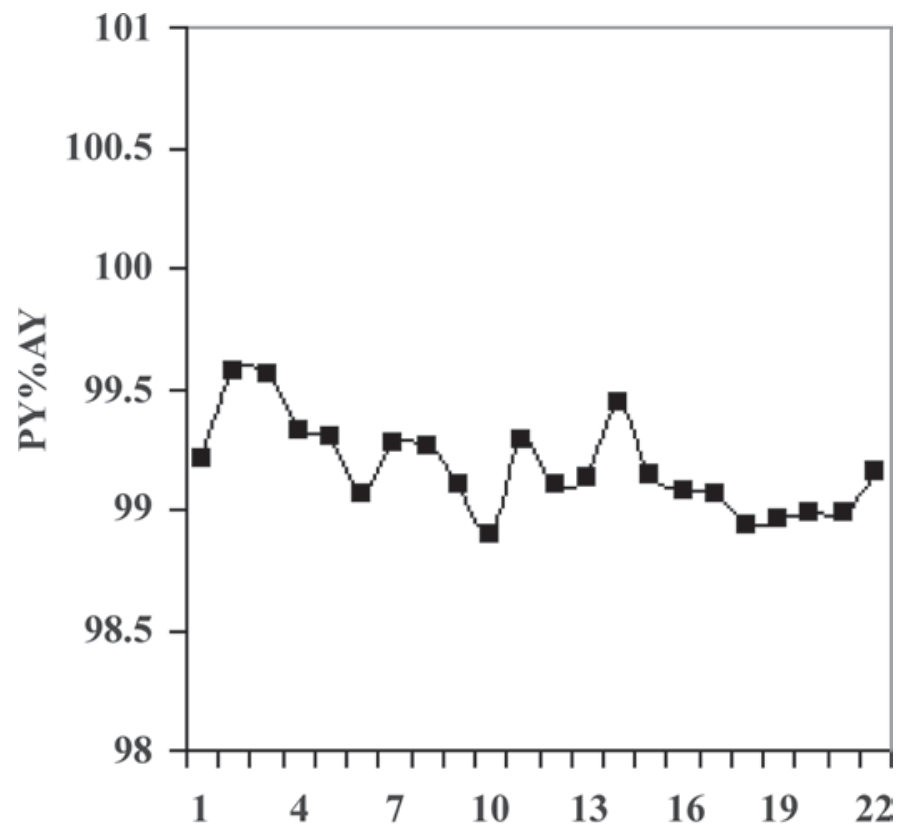

Chronological Vat Number

Figure 2. Predicted yields of cheese in 22 vats as percentages of actual yield $(\mathrm{PY} \% \mathrm{AY})$ using paracasein $(\mathrm{N} \times 6.31)$ in the General formula. They are displayed in chronological order from May to December, showing possibilities as a control chart for uniformity of sampling and analysis.

\section{Possible Systematic Errors in Analysis}

Table 2 gives a close look at the SofC and PY\%AY after adjustments to various components. The greatest effect was going from an $\mathrm{N}$-conversion factor of 6.31 to one of 6.38 - the SofC became $99.77 \%$. A few N recoveries of ammonium sulfate were performed during the analyses, and their mean was $99.51 \%$. The SofC increased to $99.89 \%$, and the procedure of the International Dairy Federation (1986) for N analysis allows a range of 99 to $100 \%$ in $\mathrm{N}$ recoveries. A subsequent experiment (Emmons et al., 2001b) found that a large increase in drying time increased the percentage $\mathrm{M}$ and the SofC by $0.082 \%$; it is not known what this means in respect to the findings of Jans (page 530, van den Berg et al., 1996), who found that the drying procedure seemed to remove some organic acids from the cheese. The mean recoveries of SC in a solution were low by a mean of $0.062 \%$; this amount increased the SofC to $100.03 \%$ and the PY\%AY to $100.04 \%$. Adjustment using only an $\mathrm{N}$-conversion factor of 6.445 gave a SofC of $100.02 \%$ and a mean PY\%AY of $100.00 \%$. These approaches to solve the discrepancy of the SofC from $100 \%$ seemed to promise many problems and to do nothing to remove the variability in the SofC among

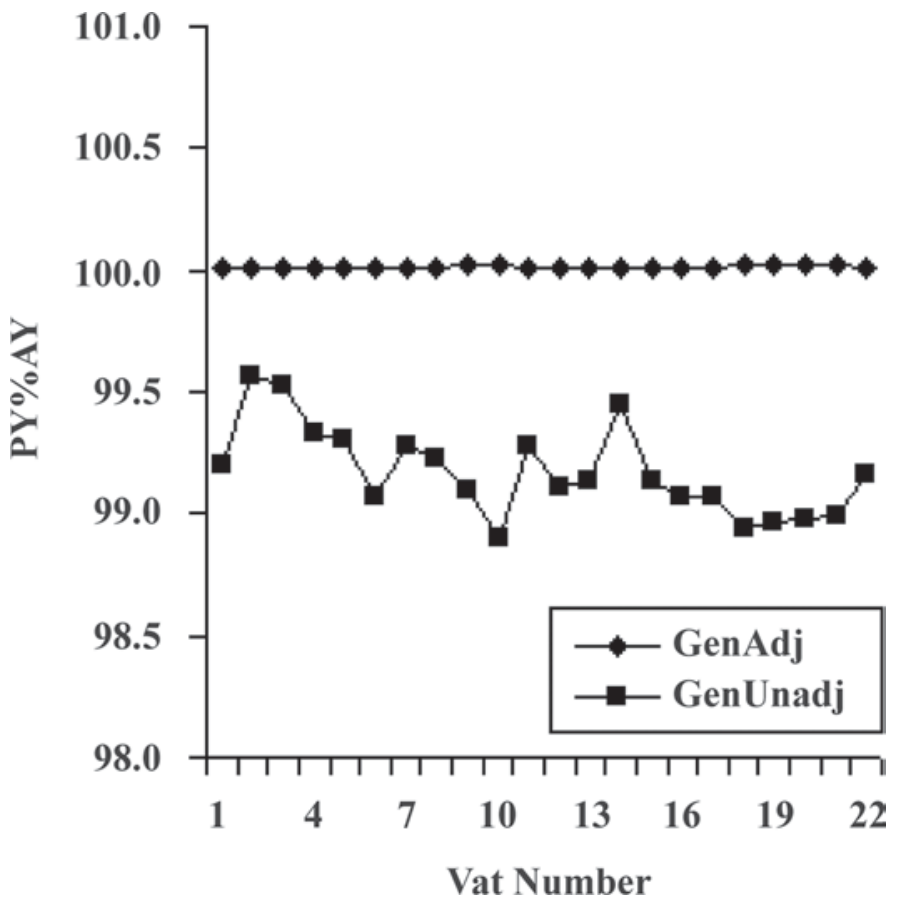

Figure 3. Predicted yields of cheese in 22 vats as percentages of actual yields $(\mathrm{PY} \% \mathrm{AY})$ using paracasein $(\mathrm{N} \times 6.31)$ in the unadjusted General formula (GenUnadj) as in Figure 2, and PY\%AY in which predicted yield is calculated using the General formula adjusted (GenAdj) using the sum of components in the cheese in each vat. 
vats; the SD values were unchanged. Other solutions were tried, as follows.

\section{Right Questions?}

On a more positive note, are the right questions being asked? Do other studies show the same problem with achieving $100 \%$ in the SofC? Is less than 100\% in the SofC a reality, and perhaps a widespread reality? Can one accept this as a reality? What can one do to accommodate low values of SofC?

We could not find many studies with enough data to compare. Table 3 contains estimates of SofC in 4 studies; they ranged from 99.2 to $100.2 \%$. Of the 15 trials, 12 showed SofC values of less than $100 \%$. Estimates of $\mathrm{ms}$ in cheese were protein $\times 0.08$. The ffpfWS values in cheese were estimated using the mean ffpfWS value in whey of $5.684 \%$ from this review; calculation used: $\mathrm{M} \times$ ffpfWS $/(1-$ ffpfWS $)-[h \times$ cas $\times$ KcasPr $\times$ ffpfWS/(1 - ffpfWS $)] /$ actual yield. It was decided to proceed on the assumption that it may be a reality that SofC values are less than $100 \%$, certainly in this review, and probably elsewhere. It is evident that the following commentary in this review is likely pertinent elsewhere.

Official methods of analyses are important to the function of the dairy industry, but it appears that one should not assume that they measure $100 \%$ of the component in question.

\section{Relationship Between SofC and PY\%AY}

The next question is whether a relationship exists between the observed SofC based on analysis of cheese and the calculated PY\%AY. Figure 1 shows that a very close relationship existed between them in the 22 vats of this review. A low PY\% AY value was associated with, and apparently due to, a low percentage of SofC. This is probably the most important observation in this review. One can conclude, then, that variations in $\mathrm{PY} \% \mathrm{AY}$ are due to variations in analysis.

Intuitively, one would deduce that underestimation of a component in cheese or milk would result in a lower predicted yield; this is, however, the first indication of a straight-line relationship between PY\%AY and SofC. Another important observation from Figure 1 is that the PY\%AY ranged from 89.9 to $99.6 \%$. One concludes then that the predictive yield formula, by itself, did not predict yields very well.

\section{Control Chart}

The chronological variation in PY\% AY in Figure 1 is shown in Figure 2, as the experiment progressed from
May to November. The variation reflects the variation in estimation of the components of cheese as the experiment progressed and, as such, would be a useful new tool as a control chart.

\section{Adjustment of Yield Formulas}

The predicted yield could be adjusted to account for differences in SofC. This was done by dividing each measured part of the General formula by the SofC (as a fraction) for that vat: fat, pc, M, SC, and ffpfWS. For example, the SofC for vat 1 was $99.54 \%$ (0.9954), that for vat 2 was $99.76 \%$ (0.9976), and so on. Figure 3 shows the PY\%AY values before and after those adjustments. The lower curve was before adjustment (see Figure 2) and the upper curve was after adjustment. The adjusted predicted yields equaled the actual yields, which was surprising to the authors. It indicates that the adjusted General formula accurately predicted yields.

One can conclude tentatively from this and subsequent observations that variations in the PY\% AY are due to variations somewhere in the analytical system. It appears that variations about a mean are due to analytical variability. Because of this, one must be cautious about inferring differences in unadjusted predicted yields to treatments in experiments. In addition, it appears that deviations of means of PY\%AY from $100 \%$ are systematic; for example, deviations associated with different N-conversion factors (Table 2).

Table 2. Effect of cumulative adjustments of components on the means of predicted yields as percentages of actual yields (PY\%AY), their sums of components (SofC), and the effect on both using only $\mathrm{N} \times 6.445$, and standard deviations (SD) in 22 vats of cheese of this review

\begin{tabular}{lrr}
\hline Cumulative adjustment & $\begin{array}{c}\text { PY\%AY } \\
(\%)\end{array}$ & $\begin{array}{c}\text { SofC } \\
(\%)\end{array}$ \\
\hline None $(\mathrm{N} \times 6.31)$ & 99.17 & 99.51 \\
SD & 0.19 & 0.12 \\
Plus protein $(\mathrm{N} \times 6.38)$ & 99.61 & 99.77 \\
SD & 0.18 & 0.12 \\
Plus N recovery (mean 99.51\%) & 99.79 & 99.89 \\
SD & 0.18 & 0.12 \\
Plus moisture $(+0.082 \%)$ & 99.94 & 99.97 \\
SD & 0.18 & 0.12 \\
Plus salt $(+0.062 \%)$ & 100.04 & 100.03 \\
SD & 0.17 & 0.11 \\
Only protein $(\mathrm{N} \times 6.445)$ & 100.00 & 100.02 \\
SD & 0.18 & 0.11 \\
\hline
\end{tabular}


Table 3. Calculated sums of components in Cheddar cheese from 4 published experiments and the levels of milk salts (ms) associated with the protein in cheese and of fat-free, protein-free whey solids (ffpfWS) estimated using factors from this review

\begin{tabular}{|c|c|c|c|}
\hline Experiment and treatment & $\begin{array}{c}\text { Sum of } \\
\text { components }(\%)\end{array}$ & $\begin{array}{l}\text { Estimated } \\
\text { ms }^{1} \text { in } \\
\text { cheese }(\%)\end{array}$ & $\begin{array}{l}\text { Estimated } \\
\text { ffpfWS }^{2} \text { in } \\
\text { cheese }(\%)\end{array}$ \\
\hline \multicolumn{4}{|l|}{ Experiment $1^{3,4}$} \\
\hline Treatment 1 & 99.7 & 1.99 & 1.50 \\
\hline Treatment 2 & 99.4 & 2.01 & 1.45 \\
\hline Treatment 3 & 99.4 & 2.01 & 1.45 \\
\hline Treatment 4 & 99.2 & 2.05 & 1.40 \\
\hline \multicolumn{4}{|l|}{ Experiment $2^{5}$} \\
\hline Treatment 5 & 99.5 & 1.92 & 1.65 \\
\hline Treatment 6 & 99.7 & 1.95 & 1.65 \\
\hline Treatment 7 & 99.9 & 2.00 & 1.59 \\
\hline Treatment 8 & 99.7 & 1.98 & 1.64 \\
\hline \multicolumn{4}{|l|}{ Experiment $3^{6}$} \\
\hline Treatment 9 & 99.3 & 3.14 & 1.83 \\
\hline Treatment 10 & 99.9 & 2.66 & 1.76 \\
\hline Treatment 11 & 100.2 & 2.49 & 1.70 \\
\hline Treatment 12 & 100.1 & 2.08 & 1.64 \\
\hline \multicolumn{4}{|l|}{ Experiment $4^{7}$} \\
\hline Treatment 13 & 100.2 & 1.50 & 1.67 \\
\hline Treatment 14 & 99.8 & 2.00 & 1.67 \\
\hline Treatment 15 & 99.7 & 2.11 & 1.70 \\
\hline
\end{tabular}

${ }^{1} \mathrm{~ms}=0.0798 \times \%$ protein in cheese.

${ }^{2}$ ffpfWS $=(\%$ moisture $/ 100-h \times \%$ protein $/ 100) \times \%$ ffpfWS $/ 100 /(1-\%$ ffpfWS $/ 100)$, where $h$ (soluteexclusion factor $)=0.406$ and ffpfWS $=5.684 \%$, from this review, except for the ffpfWS values in Experiment

${ }^{3} \mathrm{ffpfWS}$ values were from total solids, fat, and protein values in the wheys of this experiment.

${ }^{4}$ Neocleous et al. (2002).

${ }^{5}$ Barbano and Sherbon (1984).

${ }^{6}$ Fenelon and Guinee (1999).

${ }^{7}$ Guinee et al. (2007).

\section{Comparison of Yield Formulas}

It is appropriate to compare some yield formulas. Figure 4a compares the PY\%AY values for the General and Barbano formulas; greater variation in PY\% AY existed in the latter. Figure $4 \mathrm{~b}$ compares the normalized Barbano (Neocleous et al., 2002) and Van Slyke formulas; the PY\%AY values for both were more variable than those in Figure 4a. Normalization is described in a later section.

Table 4 shows the means of unadjusted PY\%AY and their standard deviations for the 4 formulas. The mean with the Van Slyke formula was closest to $100 \%$, followed closely by the Barbano formula with normalization of fat recovery. The SD values reflect the variability or spread in the PY\%AY in Figure $4 \mathrm{a}$ and $4 \mathrm{~b}$; the SD was $0.18 \%$ with the General formula and ranged from 0.29 to $0.34 \%$ for the others. The higher SD with the Barbano formula than with the General formula was likely due to the constant 0.1 in the (casein - 0.1) portion in the former formula. Introduction of the mean of KcasPr as a constant in the General formula increased the SD from 0.18 to $0.29 \%$, compared with the $0.29 \%$ with the Barbano formula.
The predicted yields were adjusted for the SofC. The middle column in Table 4 used the sums of analyzed cheese components. The mean values for PY\%AY with the General and Barbano formulas were closer to $100 \%$. The SD of the PY\%AY with the General formula was reduced to $0.03 \%$ but those for the Barbano and harmonized Barbano formulas did not change much.

In the third column, each formula was adjusted using the SofC estimated from the formulas. The mean PY\%AY values were all $100 \%$ and the SD values were $0.018 \%$ or less.

\section{Estimation of Cheese Composition by the Yield Formula}

A method was used for adjusting the yield formulas other than using the measured SofC in cheese. It was possible to estimate the composition of the cheese by the formulas themselves, as noted above. Table 5 illustrates this with the Barbano formula. Fat in cheese was estimated as fat in milk $\times \mathrm{Kf}$, divided by actual yield. Protein was (cas -0.1 ) divided by actual yield. The M and SC were as analyzed. The ms fraction was protein $\times 0.09$. The whey solids fraction was $\mathrm{C}$ from the Barba- 


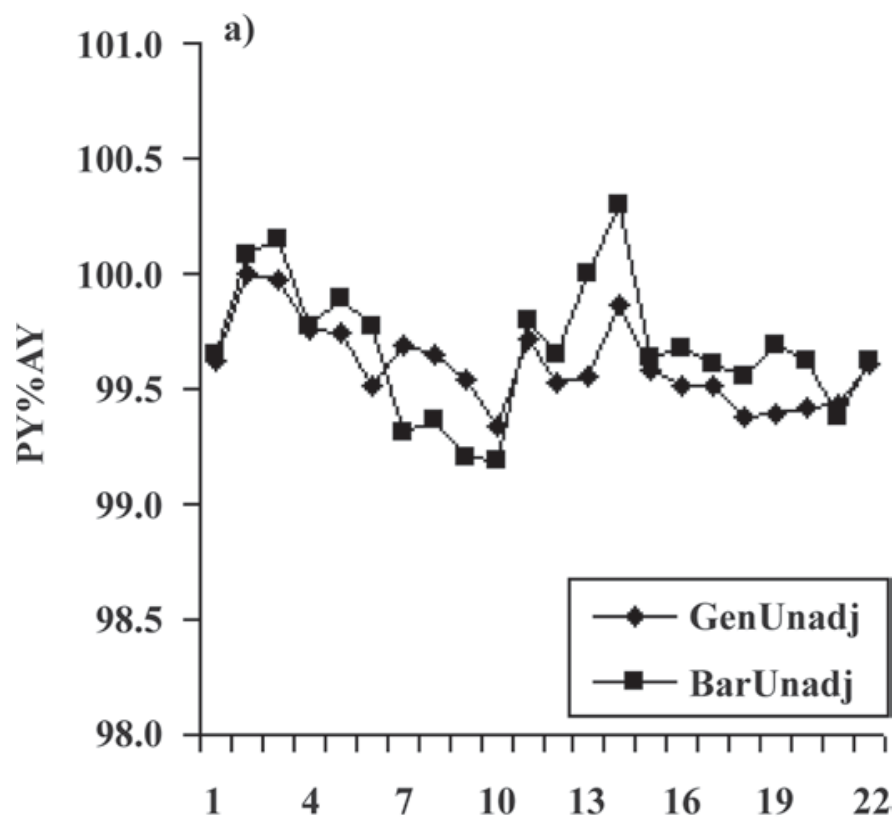

Vat Number

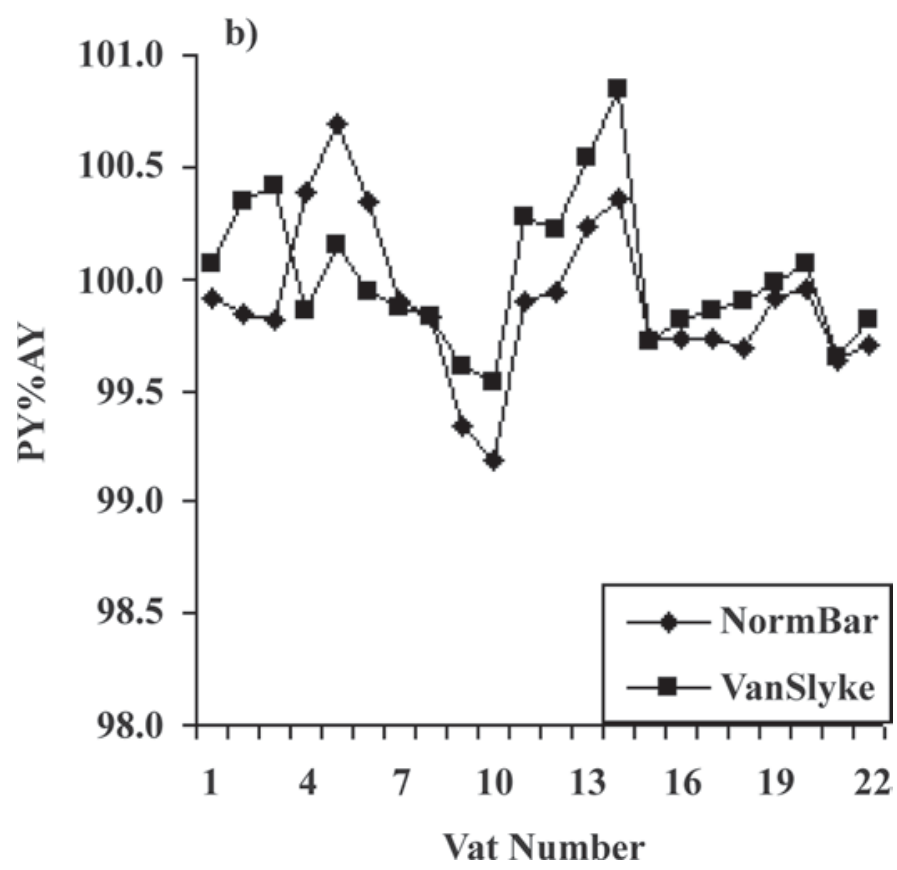

Figure 4. Predicted yields of cheese in 22 vats as percentages of actual yields (PY\%AY) using (a) the unadjusted General (Gen) and Barbano (Bar) formulas and (b) the normalized Barbano (NormBar) and the Van Slyke formulas. Casein $(\mathrm{N} \times 6.38)$ was used.

no formula, divided by actual yield. These components were as fractions, and the total was 0.9975 .

The same procedure was used for the General formula, where ffpfWS equaled $[\mathrm{M} \times \mathrm{ffpfWS} /(1-\mathrm{ffp}-$
fWS $)-(h \times$ cas $\times$ KcasPr $\times$ ffpfWS $\times(1-$ ffpfWS $) /$ actual yield]. The ms was protein $\times$ the ms part of Kms, namely 0.0798 . Protein was cas $\times \mathrm{KcasPr} /$ actual yield for each vat where $\mathbf{K c a s P r}$ was the recovery factor for milk cas in cheese.

Use of the yield formula was a new technique for estimation of the composition of cheese. Note that the procedure used actual yield in estimation of SofC.

The importance of the source of the SofC was illustrated in Figure 5, as well as in Table 4. Figure 5a shows a relatively poor relationship between the PY\%AY using the Barbano formula and the SofC as analyzed in the cheese, compared with that relationship using the General formula in Figure 3. Figure 5b showed a very good relationship between those same values for PY\%AY and the SofC estimated as in Table 5; note the range in PY\%AY from 99.3 to 100.2 in Figure 5b. Figure $5 \mathrm{c}$ used the General formula, with a range of 99.3 to 100.00 in PY\%AY, compared with the range from 89.9 to $99.6 \%$ in Figure 1 where an N-conversion factor of 6.31 was used. These are further illustrations of imperfect prediction by yield formulas without adjustment. Figure 6 shows that estimates of SofC with the General formula are closer to the SofC obtained by cheese analysis than those with the Barbano formula. It is interesting that, in spite of the differences in Figure 6 , the adjustment with both formulas enabled prediction of actual yield (Table 5). An N-conversion factor of 6.38 and cas were used.

In considering the information in Figures 5 and 6 , it is apparent that relationships of adjusted PY\% AY values are generally closer to $\mathrm{SofC}$ values derived from the formulas. Comparison of the 2 estimations of SofC may reveal inconsistencies in sampling and analysis.

Table 6 compares compositions estimated by the formulas. The left column is measured cheese composition. Components in the second column were estimated using the General formula; they are virtually identical to the analyzed values. Those in the third column were estimated using the Barbano formula. The $24.07 \%$ for protein was less than the $24.25 \%$ estimated by cheese analysis and by the General formula in columns 1 and 2 of the data, respectively. Similarly, the ffWS was less at $1.46 \%$ compared with 1.54 and $1.53 \%$ ffpfWS. On the other hand, ms was higher at $2.21 \%$, compared with $1.94 \%$ for the other two. The relationships among these components in the formula are apparently important in estimating the composition of the cheese from the formula. The difference in estimated protein content limited the usefulness of the Barbano formula in a later application. The fourth column used the adjusted General formula for calculating composition; the components were slightly higher because the formula had 
Table 4. Comparison of the predicted yields, as percentages of actual yields (PY\%AY), using the General, Barbano, Barbano with normalized fat recovery (NormBarb), and Van Slyke formulas ${ }^{1}$

\begin{tabular}{lccc}
\hline Formula & $\begin{array}{c}\text { Unadjusted } \\
\text { PY\%AY }\end{array}$ & $\begin{array}{c}\text { PY\%AY adjusted } \\
\text { for SofC from } \\
\text { cheese analysis }\end{array}$ & $\begin{array}{c}\text { PY\%AY adjusted } \\
\text { for SofC estimated } \\
\text { from formula }\end{array}$ \\
\hline General & 99.61 & 99.98 & 100.006 \\
SD & 0.18 & 0.03 & 0.003 \\
Barbano & 99.68 & 100.05 & 100.096 \\
SD & 0.29 & 0.22 & 0.015 \\
NormBarb & 99.90 & 100.27 & 100.085 \\
SD & 0.34 & 0.31 & 0.018 \\
Van Slyke & 100.01 & $\mathrm{NC}^{2}$ & 100.000 \\
SD & 0.32 & & 0.004 \\
\hline
\end{tabular}

${ }^{1}$ Yields were predicted with and without adjustment for sums of components (SofC) as analyzed in cheese and for SofC as estimated from the formulas themselves (see Table 5). Casein and $\mathrm{N} \times 6.38$ were used.

${ }^{2} \mathrm{NC}=$ not calculated.

been adjusted and they totaled $100 \%$. It is apparent that neither the General or the Barbano formula alone predicts yield; they need to be adjusted with the appropriate SofC.

The ideas that one can estimate cheese composition and the SofC using the yield formulas, that one can adjust yield formulas using those SofC values, and that those adjusted formulas accurately predicted yield, were surprising and new to the authors. It should be noted that this exercise of estimating yield required calculation of SofC, which in turn required use of actual yield for each vat (Table 5). The necessity of using actual yield restricts this use of yield prediction. An application of yield prediction is described later in which an average or typical SofC is used.

Until this point in the paper, the unadjusted predicted yield was used as part of a control chart for uniformity of component analyses, for estimation of cheese composition, and as the preliminary step to an adjusted yield formula.

\section{Use of Paracasein, Casein, and Milk Protein in General Formula}

Paracasein, cas, and mp can be used in the General formula; Table 7 compares the 3 sources of protein. The values for PY\%AY were identical for all 3 sources in all 22 vats. This means that the predicted yields themselves were identical. The reason is likely that the recovery factors for fat and pc, cas, or mp used the same values for cheese protein and weights of milk and cheese; the source of protein in milk (i.e., pc, cas, or $\mathrm{mp}$ ) and its recovery factor balance out. The prospect of being able to predict yield using $\mathrm{mp}$ instead of cas or pc was interesting, in situations when neither pc nor cas can be measured. Adjustment of the formula using the SofC from the formula as in Table 5 yielded $100 \%$ PY\%AY in all vats. It is likely that true milk protein could be used as well.

The mean values for recovery factors for pc, cas, $\mathrm{mp}$ (KmpPr), and fat were 0.9970, 0.9647, 0.7488,

Table 5. Estimation of the composition of cheese using the Barbano formula for fat, protein, moisture, salt, milk salts, and fat-free whey solids (ffWS), and using the actual yield of cheese (AY)

\begin{tabular}{llc}
\hline $\begin{array}{l}\text { Cheese } \\
\text { component }\end{array}$ & Calculation & $\begin{array}{c}\text { Estimated cheese } \\
\text { composition } \\
\text { (as fractions) }\end{array}$ \\
\hline Fat & $\%$ fat in milk $\times \mathrm{Kf} / \mathrm{AY}$ & 0.3540 \\
Protein & $\%$ casein in milk -0.1$) / \mathrm{AY}$ & 0.2407 \\
Moisture & $\% / 100$ & 0.3519 \\
Salt & $\% / 100$ & 0.0146 \\
Milk salts & Protein $\times 0.09$ & 0.0217 \\
ffWS & C/AY & 0.0146 \\
Total & & 0.9975 \\
\hline
\end{tabular}

${ }^{1}$ Moisture and salt were from cheese analysis; measured values for fat and casein in milk, ffWS in whey, and Kf (fat recovery factor) and $\mathrm{C}$ (one of components in Barbano formula) were used. 

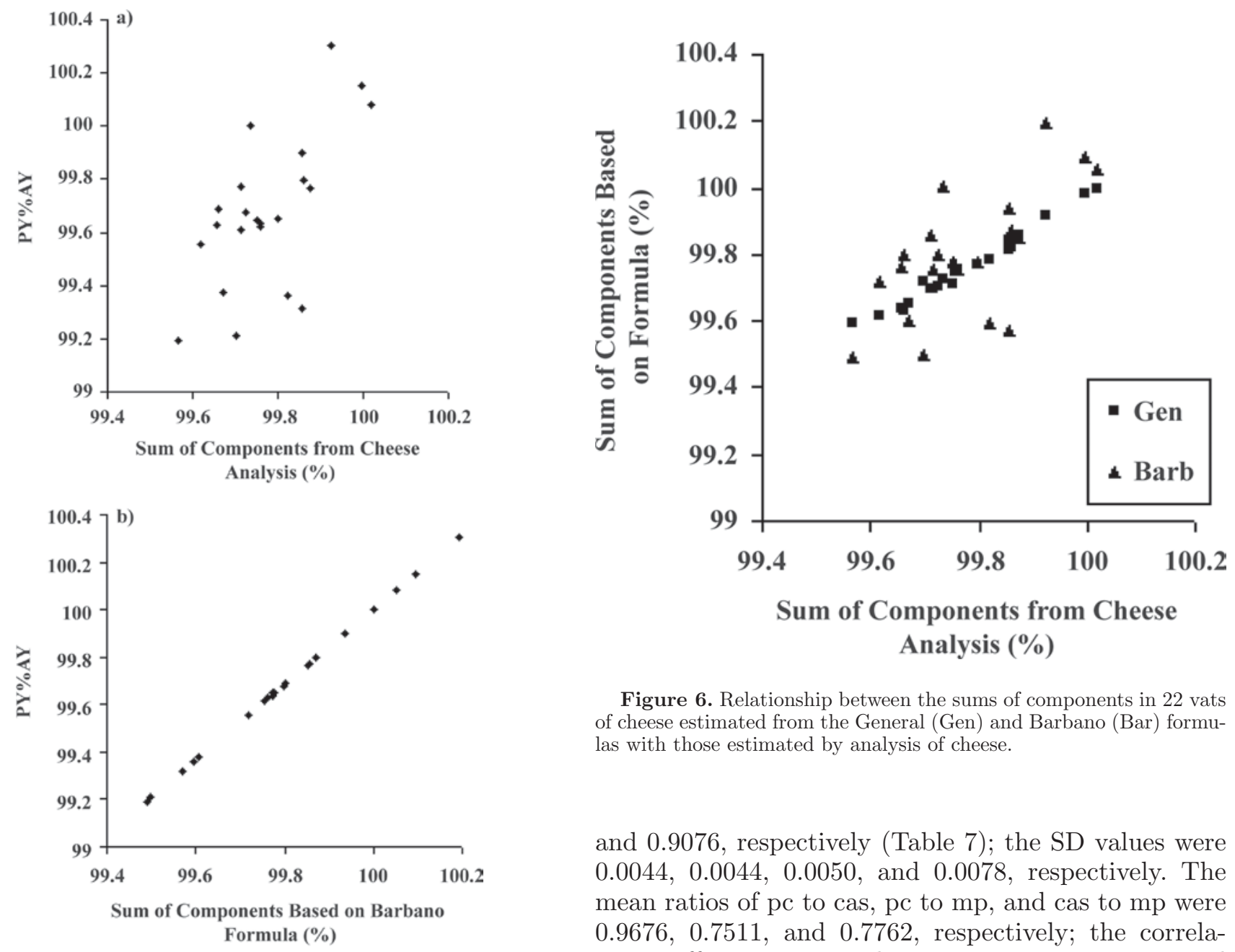

Figure 6. Relationship between the sums of components in 22 vats of cheese estimated from the General (Gen) and Barbano (Bar) formulas with those estimated by analysis of cheese.

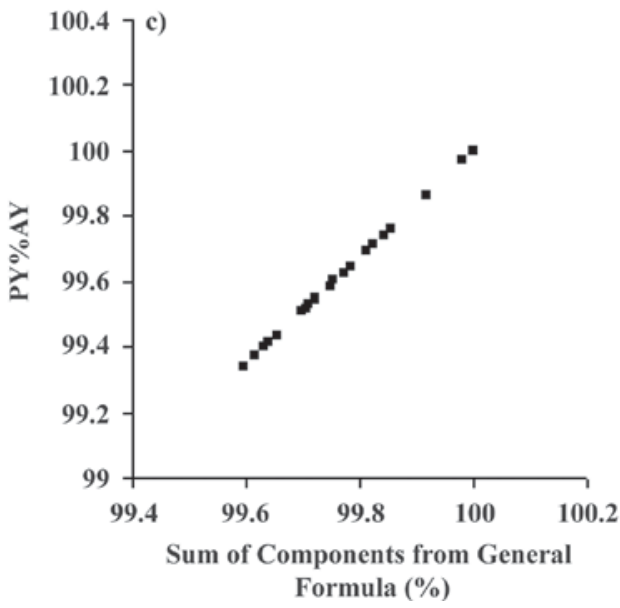

Figure 5. Relationship between predicted yields of cheese in 22 vats as percentages of actual yields (PY\%AY) using the Barbano formula and sums of components (SofC) measured in cheese (panel a). Panel $\mathrm{b}$ shows the relationship between the same PY\%AY and the SofC estimated using the Barbano formula (see Table 4), and panel c shows the relationship between the PY\% AY using the General formula and SofC estimated using the General formula. Casein $(\mathrm{N} \times 6.38)$ was used.

and 0.9076 , respectively (Table 7 ); the $\mathrm{SD}$ values were $0.0044,0.0044,0.0050$, and 0.0078 , respectively. The mean ratios of pc to cas, $\mathrm{pc}$ to $\mathrm{mp}$, and cas to $\mathrm{mp}$ were $0.9676,0.7511$, and 0.7762 , respectively; the correlation coefficients among the pairs were $0.996,0.977$, and $0.970(\mathrm{df}=9)$, respectively. The values of $h$ and $\mathrm{Kms}$ remain the same for the 3 protein sources. Figure 7 shows the close relationship between pc and cas.

\section{Paracasein Versus Casein}

It appears that pc is equal to or better than cas in the following ways. The SD of the ratios of $\mathrm{pc}$ and cas to $\mathrm{mp}$ were 0.0.0031 and 0.0037, respectively (Table 7). Moreover, pc appears to be easier to estimate than cas using infrared instruments and has been used successfully in cheese plants (van den Berg et al., 1996). However, standard procedures have yet to be elaborated for its measurement.

\section{Target Yields}

Yield formulas are used in research to adjust actual yields to yields of target composition, adjusting usually for $\mathrm{M}$ and SC. The common target compositions after adjustment make it more meaningful to compare 
Table 6. Composition of cheese estimated by analysis of cheese and estimated, as in Table 4, from the unadjusted General and Barbano formulas and from the adjusted General formula

\begin{tabular}{lcccc}
\hline & \multicolumn{4}{c}{ Method of estimation of cheese composition } \\
\cline { 2 - 5 } & $\begin{array}{c}\text { Cheese } \\
\text { analysis }\end{array}$ & $\begin{array}{c}\text { Unadjusted } \\
\text { General } \\
\text { formula }\end{array}$ & $\begin{array}{c}\text { Unadjusted } \\
\text { Barbano } \\
\text { formula }\end{array}$ & $\begin{array}{c}\text { Adjusted } \\
\text { General } \\
\text { formula }\end{array}$ \\
\hline Protein (\%) & 24.25 & 24.25 & 24.07 & 24.31 \\
Fat (\%) & 35.40 & 35.40 & 35.40 & 35.48 \\
Moisture (\%) & 35.19 & 35.19 & 35.19 & 35.27 \\
Salt (\%) & 1.46 & 1.46 & 1.46 & 1.47 \\
Milk salts (\%) & 1.94 & 1.94 & $1.46^{2}$ & $1.53^{1}$ \\
Whey solids (\%) & $1.54^{1}$ & $1.53^{1}$ & 99.75 & 100.00 \\
Total (\%) & & & &
\end{tabular}

${ }^{1}$ Fat-free, protein-free whey solids.

${ }^{2}$ Fat-free whey solids.

treatments for their effect on yield, unless of course the treatment affects the composition and hence yield.

The theoretically more correct way to determine the target yield is by using the adjusted formula below, because the adjusted predicted yield equals the actual yield. Formula for calculation of target (Tar) yield $(\mathbf{Y})$ from actual (Act) yield using predicted (Pred) yield and PredY adjusted (Adj) with the sum of components estimated from the yield formula. Adjusted formula:

$$
\frac{\text { TarY }}{\text { ActY }}=\frac{\text { AdjPredTarY }}{\text { AdjPredY }}
$$

or

$$
\text { TarY }=\text { ActY } \times \text { AdjPredTarY } / \text { AdjPredY } .
$$

Unadjusted formula:

$$
\frac{\operatorname{Tar} Y}{\text { Act } Y}=\frac{\text { PredTarY }}{\text { PredY }}=\frac{\frac{(\text { fat,cas,etc. })}{(1-\text { TarM }- \text { TarSC })}}{\frac{(\text { fat,cas,etc. })}{(1-\mathrm{M}-\mathrm{SC})}}
$$

or

$$
\frac{\operatorname{Tar} Y}{\text { ActY }}=\frac{\text { PredTarY }}{\text { PredY }}=\frac{\frac{(\text { fat,cas,etc. })}{(1-\text { TarM }- \text { TarSC }- \text { calWS })}}{\frac{(\text { fat,cas,etc. })}{(1-\mathrm{M}-\mathrm{SC}-\text { calWS })}}
$$

or

$$
\text { TarY }=\text { ActY } \times \text { PredTarY } / \text { PredY } .
$$

If there are no targets in the numerator, then

$$
\operatorname{TarY}=\operatorname{ActY} \times(1-\mathrm{M}-\mathrm{SC}) /(1-\mathrm{TarM}-\mathrm{TarSC})
$$

or

$$
\operatorname{Tar} Y=\frac{\operatorname{Act} Y \times(1-\mathrm{M}-\mathrm{SC}-\mathrm{calWS})}{(1-\mathrm{Tar} \mathrm{M}-\mathrm{TarSC}-\mathrm{calWS})},
$$

where (fat, cas, etc.) $=$ numerator in the General or Barbano formulas and calWS $=$ calculated whey solids

Table 7. Comparison of paracasein (pc), casein (cas), and total milk protein $(\mathrm{mp})$ in the General formula in their effect on predicted yield as a percentage of actual yield (PY\%AY), recovery factors as protein in cheese (KpcPr, KcasPr, $\mathrm{KmpPr}$, respectively), their ratios and correlation coefficients

\begin{tabular}{lll}
\hline Item & Mean & SD \\
\hline PY\%AY $(\%)$ & & \\
pc/cas & 0.00 & 0.00 \\
pc/MP & 0.00 & 0.00 \\
cas/MP & 0.00 & 0.00 \\
Recovery factors ${ }^{3}$ & & \\
KpcPr & 0.9970 & 0.0044 \\
KcasPr & 0.9647 & 0.0044 \\
KmpPr & 0.7488 & 0.0050 \\
Kf (fat recovery) & 0.9076 & 0.0078 \\
Ratio & & \\
pc/cas & 0.9676 & 0.0018 \\
pc/mp & 0.7511 & 0.0031 \\
cas/mp & 0.7762 & 0.0037 \\
Correlation coefficient & & \\
pc and cas & & \\
pc and mp & $0.996^{4}$ & \\
cas and mp & $0.977^{4}$ & \\
\hline
\end{tabular}

${ }^{1}$ The $\mathrm{N}$-conversion factor was 6.38 in all cases. The $h$ (solute-exclusion factor) and $\mathrm{Kms}(1+$ ratio of milk salts to protein in cheese) values and the 3 sources of protein were as measured in each vat.

${ }^{2}$ Comparison of $\mathrm{PY} \% \mathrm{AY}$ using pc, cas, and $\mathrm{mp}$ on each vat.

${ }^{3}$ Recovery of pc, cas, or $\mathrm{mp}$ as protein in cheese.

${ }^{4} P>0.99 ;$ df $=9$. 


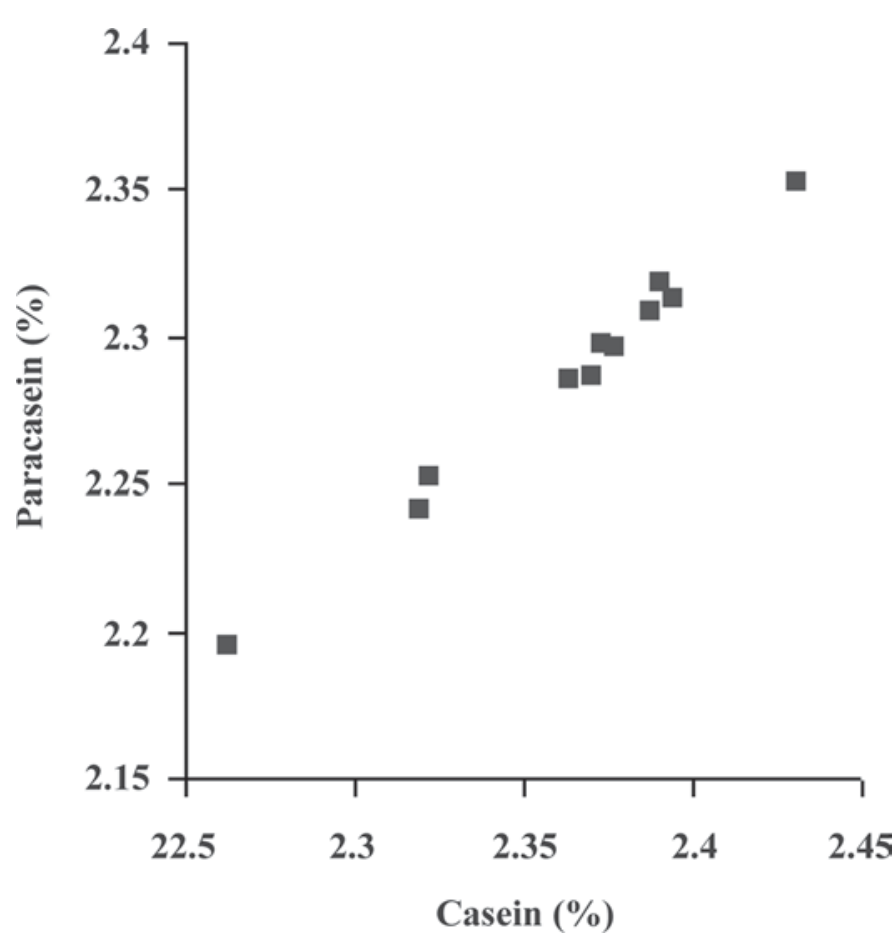

Figure 7. Relationship between paracasein and casein in 11 lots of milk using $\mathrm{N} \times 6.38$.

in cheese $[=\mathrm{M} \times \mathrm{ffpfWS} /(1-\mathrm{ffpfWS})$; General formula].

The ratio of the target yield to the actual yield equals the ratio of the predicted yield using the target composition to that using the actual composition, both using the adjusted predictive formula. If the unadjusted formula is used, two things need to be considered. First, if the yield formula has no targets in the numerator, the numerators cancel and the target yield equals the calculation in the bottom part of the table. But we are not aware of any predictive formula with $(1-\mathrm{M}-$ $\mathrm{SC}$ ) in the denominator without a target value in the numerator, except an unused modification (Emmons, 1996) of the Van Slyke and Price (1949) formula. The Barbano formula has $\mathrm{M}$ in the numerator, so use of the full formula is indicated. Second, M and SC are not in the numerator of the General formula so the lower equation may be used, but the term calculated whey solids (calWS) is added to the denominator.

The use of these alternatives is illustrated in Table 8. Targets were $38 \% \mathrm{M}$ and $1.8 \% \mathrm{SC}$, compared with means of $35.2 \% \mathrm{M}$ and about $1.5 \% \mathrm{SC}$ in the 22 vats. The targets in the left column of data used unadjusted and adjusted General and Barbano formulas. As expected, the mean target of $9.893 \mathrm{~kg}$ was less with (1 $\mathrm{M}-\mathrm{SC}$ ). In addition, the target yield of $9.940 \mathrm{~kg}$ using
(1 - M - SC - calWS) was the same as that using the unadjusted General formula in the right column and marginally less that the $9.943 \mathrm{~kg}$ using the adjusted General formula in both columns. As expected, the predicted target yield of $9.943 \mathrm{~kg}$ was the same in both columns for the General formula adjusted for SofC. The differences using the Barbano formula were not as clear because the higher $M$ involved a change in calculated sef. One concludes that the preferred method of estimating target yields used adjusted yield formulas.

The exercise in Table 8 was repeated with targets of $35.5 \% \mathrm{M}$ and $1.5 \% \mathrm{SC}$; the means of the observed values in the experiments were 35.19 and $1.46 \%$, respectively. The equivalents to the means of 9.893, 9.940, and 9.943 $\mathrm{kg}$ in the middle of Table 8 were 9.454, 9.458, and 9.458 $\mathrm{kg}$, respectively; the difference was $0.004 \mathrm{~kg}$ in the latter group, compared with a difference of $0.050 \mathrm{~kg}$ in the former group. The degree of difference using the ratio of $(1$ - ActM - ActSC)/(1 - TarM - TarSC) from the other methods of calculating targets was less when the difference between the actual and target values was less.

\section{Cheese Yield Efficiency}

Cheese yield efficiency (CYE) compares a cheese yield with a target yield of desired or target composition, and equals actual yield $\times 100$ divided by the adjusted target yield. Estimation of CYE is likely one of the major applications of yield formulas in industry. The difference between the target yields using the (1 - M - SC) ratio and those with the adjusted General formula was $0.05 \mathrm{~kg}$ of cheese per $100 \mathrm{~kg}$ of milk in Table 8, where the difference in moisture was $3.0 \%$. A difference of $0.5 \%$ in target yield would seem to be important commercially.

\section{Prediction of Composition and Yield of a New or Different Cheese}

An interesting application of target yields is illustrated in Table 9. This application predicts composition and yield, for example, of a new cheese containing $45 \%$ $\mathrm{M}$ and $2 \%$ SC. This application used mean compositions of milk, whey, and cheese, and mean recoveries of fat and cas from this review. This application also used the mean SofC in the experiment of 0.99758; in practice, it would require prior knowledge of a typical or mean SofC for the plant.

As shown in footnote 2 of Table 9, first, a preliminary adjusted yield was calculated using the mean of the SofC from the experiment, 0.99758 as $11.4587 \mathrm{~kg}$. The estimated composition was calculated using 11.4587 as 
Table 8. Mean target (Tar) yields (Y, $\mathrm{kg}$ of cheese/100 kg of milk) in 22 vats of cheese, adjusting to $38 \%$ moisture (M) and 1.8\% salt (SC) using different predicting (Pred) formulas, unadjusted and adjusted for the sum of components (SofC) in the cheese; casein and $\mathrm{N} \times 6.38$ were used.

\begin{tabular}{|c|c|c|}
\hline Formula $^{1}$ & $\begin{array}{c}\text { PredTarY at } \\
\text { target values }(\mathrm{kg})\end{array}$ & $\begin{array}{c}\text { PredTarY using } \\
\text { actual (Act)Y } \times \\
\text { PredTarY/PredActY }(\mathrm{kg})\end{array}$ \\
\hline $\operatorname{Act} Y \times \frac{(1-\operatorname{ActM}-\operatorname{ActSC})}{(1-\text { TarM }- \text { TarSC })}$ & 9.893 & \\
\hline $\operatorname{Act} Y \times \frac{(1-\operatorname{ActM}-\operatorname{ActSC}-\text { calWS })}{(1-\text { TarM }- \text { TarSC }- \text { calWS })}$ & 9.940 & \\
\hline General unadjusted & 9.901 & 9.940 \\
\hline General adjusted for SofC & 9.943 & 9.943 \\
\hline $\begin{array}{l}\text { Barbano unadjusted (solute- } \\
\text { exclusion factor }=0.703 \text { ) }\end{array}$ & 9.904 & 9.935 \\
\hline $\begin{array}{l}\text { Barbano adjusted for SofC (solute- } \\
\text { exclusion factor }=0.703 \text { ) }\end{array}$ & 9.947 & 9.938 \\
\hline
\end{tabular}

the actual yield as in Table 5. Fat, protein, M, SC, ms, and ffpfWS were 29.05, 19.89, 45, 2, 1.59, and 2.22\%, respectively. The SofC was 0.99753 . The adjusted yield was calculated as $11.46 \mathrm{~kg}$ of cheese using the General formula adjusted for a SofC of 0.99753. The predicted yield using the unadjusted formula was $11.40 \mathrm{~kg}$; the adjusted yield of $11.46 \mathrm{~kg}$ was $0.5 \%$ higher. The Barbano formula was not used here because of the skewed composition that would have resulted, as shown earlier in Table 6 .

Using the ratio of $(1-\operatorname{ActY}-\operatorname{ActSC}) /(1-$ TarM TarSC) in Tables 10 and 11, the yield, adjusted to $45 \%$ $\mathrm{M}$ and $2 \% \mathrm{SC}$, was calculated starting with the means of actual yield of $9.402 \mathrm{~kg}, 35.19 \% \mathrm{M}$, and $1.46 \% \mathrm{SC}$. That estimated yield was $11.20 \mathrm{~kg}$, compared with the $11.46 \mathrm{~kg}$ calculated using the adjusted General formula.

Table 9. Prediction of adjusted yield using the adjusted General formula and prediction of composition of cheese using unadjusted General formula, first for prediction of unadjusted yield and then for calculation of the composition using that formula ${ }^{1}$

\begin{tabular}{lc}
\hline Item & \\
\hline Target composition: & $45 \%$ moisture; $2 \%$ salt \\
Predicted yield using adjusted General formula $^{1,2}$ : & $11.46 \mathrm{~kg}$ of cheese \\
Predicted yield and composition using unadjusted General $^{1}$ & \\
formula $^{1}$ & \\
Yield (unadjusted) (kg) & 11.40 \\
Fat (\%) & 29.05 \\
Moisture (\%) & 19.89 \\
Salt (\%) & 45.00 \\
Milk salts (\%) & 2.00 \\
ffpfWS (\%) & 1.59 \\
& 2.22 \\
Total (\%) & 99.75 \\
\hline
\end{tabular}

${ }^{1}$ Means of factors in this experiment were used as appropriate. Mean values for composition and constants: fat in milk $=3.667 \%$; milk fat recovery as cheese $=0.9076$; casein in milk $=2.303 \%$; recovery of casein as cheese protein $=0.9647$; recovery of milk salts as cheese $=0.0798$; solute exclusion factor $=0.4068$; fat-free, proteinfree solids in whey (ffpfWS) $=5.684 \%$; moisture was $45 \%$ and salt was $2 \%$.

${ }^{2}$ Calculate preliminary adjusted yield (AY) using the mean of the sum of components (SofC) from the experiment of 0.99758 , giving $11.4587 \mathrm{~kg}$. Calculate the estimated composition using $11.4587 \mathrm{~kg}$ as the AY, as in Table 4; the SofC was 0.99753; using that SofC, the AY was calculated as $11.4600 \mathrm{~kg}$. 
Table 10. Assessment of the possibility of predicting yield of cheese (predicted yield as percentage of actual yield, PY\%AY) where analyses of protein and fat in cheese and of casein or paracasein in milk were not available $^{1}$

\begin{tabular}{|c|c|c|c|c|}
\hline Constant $^{2}$ & $\begin{array}{c}\text { No } \\
\text { adjustments, } \\
\text { PY\%AY }\end{array}$ & $\begin{array}{c}\text { Adjusted by } \\
\text { SofC of } \\
0.9976, \text { PY\%AY }\end{array}$ & SofC & $\begin{array}{l}\text { Adjusted } \\
\text { for SofC, } \\
\text { PY\%AY }\end{array}$ \\
\hline None & 99.606 & & 0.9976 & 100.006 \\
\hline $\mathrm{SD}$ & 0.195 & & 0.0012 & 0.003 \\
\hline Means of Kf and $\mathrm{KmpPr}$ & 99.610 & 100.008 & 0.9976 & 100.006 \\
\hline $\mathrm{SD}$ & 0.650 & 0.652 & 0.0040 & 0.011 \\
\hline Kf, $0.89 ; \mathrm{KmpPr}, 0.745$ & 98.271 & & 0.9894 & 100.029 \\
\hline SD & 0.632 & & 0.0039 & 0.011 \\
\hline
\end{tabular}

${ }^{1}$ The effect on PY\%AY is shown of the use of milk protein (mp) and means or selected values of Kf and $\mathrm{KmpPr}$ as constants on PY\%AY, on sums of components (SofC), and on PY\%AY using the General formula adjusted for the SofC. Means of $h$ (solute-exclusion factor for fat-free, protein-free solids in whey by cheese protein) and $\mathrm{Kms}(1+$ ratio of milk salts associated with cheese protein to cheese protein) for the 22 vats were used as constants.

${ }^{2} \mathrm{Kf}=$ recovery of milk fat as cheese, mean $=0.9076 ; \mathrm{KmpPr}=$ recovery of milk protein as cheese protein, mean $=0.7488$.

This corroborates the earlier observation that the suitability of using that ratio depends on how close the actual and target compositions are.

It is appropriate to discuss KcasPr and $\mathrm{KpcPr}$. They are the ratios of the protein in cheese to the cas or pc in milk as measured by total $\mathrm{N} \times 6.38$ in most cases. This leads to the question of how much $\mathrm{N}$ in cheese does not originate from pc and its products, for example, whey or serum proteins. This is pertinent in Table 9, compared with the composition of cheese in Table 6. Emmons et al. (2003) estimated the $\mathrm{N}$ from serum or whey proteins to be $1 \%$ of $\mathrm{N}$ in cheese; this considered results of experiments by O'Keefe et al. (1978), de Koning et al. (1981), and Lo and Bastian (1998). The proportion of other $\mathrm{N}$ in Cheddar cheese was estimated as $0.10 \%$ caseinomacropeptide, $0.24 \%$ NPN, $0.15 \%$ proteose-peptone N, and $98.51 \% \mathrm{~N}$ from pc and its hydrolysis products. The level of $1 \%$ is approximately twice that expected from the content of whey proteins in whey. One supposes that some sort of molecular microfiltration may occur, not only to concentrate the whey proteins but also to overcome steric exclusion of serum proteins by the pc matrix ( $h$ of 2.6 for serum proteins by cas; van Boekel, 1994). In summary, KcasPr may not be the same in cheese of $45 \%$ moisture as in that of $35 \%$ moisture; on the other hand, the actual KcasPr appears not to be known at this time.

\section{Predicted Yield Where Protein and Fat in Cheese Are Not Known}

A new idea was to use means of $\mathrm{Kf}$ and $\mathrm{KmpPr}$ as constants to estimate yield of cheese using the General formula and its adjustment, where data for cas or pc in milk and fat and protein in cheese were not available (Table 10). The mean PY\%AY without adjustment was $99.606 \%$ without constants, compared with $99.610 \%$ with means of $\mathrm{Kf}$ and $\mathrm{KpmPr}$ as constants; the SD values among the 22 vats were 0.18 and $0.65 \%$, respectively. With the restriction of only $\mathrm{mp}$ and fat in milk being known, a SofC from this study of 0.9976 was used to adjust the General formula. This resulted in a mean PY\%AY of $100.008 \%$, but the SD among the 22 vats was high, at $0.652 \%$. Estimation of SofC required values for yield; they were used to estimate the SofC for each vat. A SofC of 0.9976 and a mean adjusted PY\%AY and SD of 100.006 and $0.011 \%$, respectively, resulted (Table 10).

It was surprising and encouraging that yields could be predicted where protein and fat were not known in the cheese. It should be noted though that actual yield was used to estimate SofC in the adjusted formula. The appendix contains an example of the calculation of adjusted target yield and cheese yield efficiency using the General formula where neither fat nor protein content of cheese is known and where neither pc nor cas content of milk is known (only mp is known).

Table 10 also contains data where arbitrarily selected lower constants of 0.89 for $\mathrm{Kf}$ and 0.745 for $\mathrm{KmpPr}$ were used. As expected, the mean unadjusted PY\%AY values were lower at $98.271 \%$, but the SD was about the same at 0.632 ; the mean SofC was lower at 0.9894 and the SD was about the same at 0.0039. Adjustment of the General formula gave a mean PY\%AY of $100.031 \%$ and a SD of $0.011 \%$. It is apparent in this application that the constants of $\mathrm{Kf}$ and $\mathrm{KpmPr}$ do not need to be exactly equivalent to those of the set of data. 
Table 11. Effect on predicted yield as a percentage of actual yield (PY\%AY) of using constants for 9 of the factors in the General yield formula (Eq. 1); differences of PY\%AY from that with no constants are also given

\begin{tabular}{|c|c|c|c|c|}
\hline \multirow[b]{2}{*}{ Component used as constant $^{1}$} & \multicolumn{2}{|c|}{$\mathrm{PY} \% \mathrm{AY}$} & \multicolumn{2}{|c|}{$\begin{array}{c}\text { Difference of } \\
\text { PY\%AY from } \\
\text { that with } \\
\text { no constants }\end{array}$} \\
\hline & Mean & $\mathrm{SD}$ & Mean & $\mathrm{SD}$ \\
\hline No constants & 99.606 & 0.181 & & \\
\hline ffpfWS $=0.05684$ & 99.606 & 0.180 & 0.000 & 0.018 \\
\hline$h=0.4068$ & 99.606 & 0.176 & 0.000 & 0.069 \\
\hline $\mathrm{Kms}=1.0798$ & 99.607 & 0.210 & -0.001 & 0.071 \\
\hline $\mathrm{SC}=0.0146$ & 99.606 & 0.178 & 0.000 & 0.100 \\
\hline $\mathrm{KpcPr}=0.9970$ & 99.604 & 0.290 & 0.001 & 0.205 \\
\hline $\mathrm{Kf}=0.9076$ & 99.612 & 0.529 & -0.006 & 0.501 \\
\hline $\mathrm{M}=0.3519$ & 99.606 & 0.737 & 0.000 & 0.729 \\
\hline $\mathrm{Pc}=2.286$ & 99.609 & 0.771 & -0.003 & 0.765 \\
\hline $\mathrm{FM}=3.667$ & 99.632 & 1.698 & -0.027 & 1.799 \\
\hline \multicolumn{5}{|l|}{ Combinations of constants } \\
\hline$h$ and $\mathrm{Kms}$ & 99.607 & 0.195 & -0.001 & 0.075 \\
\hline$h, \mathrm{Kms}, \mathrm{ffpfWS}$ & 99.607 & 0.191 & -0.001 & 0.071 \\
\hline$h, \mathrm{Kms}, \mathrm{KpcPr}$ & 99.607 & 0.292 & -0.001 & 0.210 \\
\hline$h, \mathrm{Kms}$, ffpfWS, KpcPr & 99.607 & 0.291 & -0.001 & 0.210 \\
\hline \multicolumn{5}{|l|}{ Rearrangement of General formula ${ }^{2}$} \\
\hline$h, \mathrm{Kms}, \mathrm{ffpfWS}(\mathrm{pc} \times 1.0553, \mathrm{M} \times 1.0603)$ & 99.606 & 0.165 & 0.008 & 0.081 \\
\hline \multicolumn{5}{|c|}{$\begin{array}{l}{ }^{1} \text { Constants were used singly and in combination with data from } 22 \text { vats. ffpfWS }=\% \text { fat-free, protein-free whey } \\
\text { solids } / 100 ; h=\text { solute-exclusion factor; Kms }=\text { factor for milk salts associated with cheese protein }(=1+ \\
\text { ratio of those milk salts to the protein in cheese); } \mathrm{SC}=\% \text { salt in cheese } / 100 ; \mathrm{KpcPr}=\text { recovery of paracasein } \\
\text { in milk as cheese protein; } \mathrm{Kf}=\text { recovery of fat in milk as cheese fat; } \mathrm{M}=\% \text { moisture in cheese } / 100 ; \mathrm{pc}=\% \\
\text { paracasein in milk; } \mathrm{N} \times 6.38 ; \mathrm{FM}=\% \text { fat in milk. } \\
{ }^{2}(\mathrm{FM} \times \mathrm{Kf}+1.0553 \times \mathrm{pc} \times \mathrm{KpcPr}) /(1-\mathrm{SC}-1.0603 \times \mathrm{M}) ;(1-\mathrm{SC})=0.9854\end{array}$} \\
\hline
\end{tabular}

\section{Constants in the General Formula}

The General formula has 9 variables: fat in milk (FM), Kf, pc, KpcPr, Kms, $h$, ffpfWS, M, and SC; mean values (and SD) were $3.667 \%(0.11), 0.9076(0.0078)$, $2.206 \%$ (0.042), 0.9970 (0.0041), 0.0798 (0.0019), 0.407 (0.029), $5.684 \%(0.037), 35.189 \%(0.423)$, and $1.464 \%$ (0.061), respectively. They were measured for each vat and used throughout, except where noted.

Table 11 shows the effect of using the mean of each of those variables as a constant in the General formula on the variability of PY\% AY among the 22 vats. The $\mathrm{SD}$ of PY\%AY values with ffpfWS, $h$, and SC were the same or less compared with that with no constants, $0.181 \%$; the SD using Kms as a constant was close at $0.210 \%$. As expected, the SD of PY\%AY values were much higher with Kf, M, pc, and FM indicating relatively wide ranges of predicted yields. The mean values of PY\% AY with each were close, at $99.61 \%$.

Table 11 also shows the SD values of differences of PY\%AY using each component as a constant compared with the PY\% AY using no constants; lower values indicate PY\% AY values closer to those with no constants. They range from a low of $0.018 \%$ with ffpfWS to a high of $1.799 \%$ with FM as constants. Other high values of $0.501,0.729$, and $0.765 \%$ were expected with $\mathrm{Kf}, \mathrm{M}$, and pc, respectively.

In most applications, it is not practical to measure all the components listed in Table 11, particularly $h$ and Kms; it would be desirable if they could be used as constants because they are difficult to measure in each vat. The use of them together resulted in a SD of $0.075 \%$, which compared closely to 0.069 and $0.071 \%$ with $h$ and Kms, respectively; it appears that they can be used as constants, certainly in this review. It would also be desirable if $\mathrm{KpcPr}$ could be used as a constant; its use as a constant would appear to depend on uniformity of cheesemaking and of the recovery of pc as protein in cheese.

The effect of using ffpfWS as a constant, $5.684 \%$ or 0.05864 as a proportion, was unexpected. The SD of differences of $0.018 \%$ using ffpfWS as a constant was the lowest, meaning that the PY\%AY values were the closest to those with no constants; its combination with $h, \mathrm{Kms}$, and $\mathrm{KpcPr}$ had no additional effect on SD of differences. The reason appears to be that the range of ffpfWS values was low among the 22 vats; the SD was $0.037 \%$. 
It is interesting that the use of ffpfWS as a constant, as well as $h$ and Kms, enabled the rearrangement of the General formula to

$$
\begin{gathered}
\mathrm{Y}=(\mathrm{FM} \times \mathrm{Kf}+1.0553 \times \mathrm{mp} \times \mathrm{KmpPr}) / \\
(1-\mathrm{SC}-1.0603 \times \mathrm{M}) .
\end{gathered}
$$

The cas, pc, and mp were used interchangeably, and the mean PY\%AY was $99.606 \%$ (SD $=0.165 \%$; Table 11). The mean PY\%AY with the rearranged formula was $0.008 \%$ less than that with the formula with no constants. The SD of those differences among the 22 vats was $0.081 \%$ (Table 11), slightly more than the 0.071 with the combination of $h, \mathrm{Kms}$, and ffpfWS as constants with the full General formula. This abbreviated formula was adjusted for the SofC of each vat to give a mean adjusted PY\% AY of $100.01 \%$ (SD = $0.0001 \%)$ for the 22 vats. The SofC values for each vat (mean of 0.9976) were estimated in the usual way but using as constants the means of 0.4068 for $h, 0.0798$ for $\mathrm{ms}$, and 0.0568 for ffpfWS in whey.

The seasonal variability of lactose, the main component of ffpfWS, is well known; Olling (1963) reported an annual range from 4.8 to $5.2 \%$ in whey, compared with a range of ffpfWS from 5.60 to $5.73 \%$ in this study from May to December. A difference in ffpfWS of $0.4 \%$ resulted in a difference of $0.018 \mathrm{~kg}$ of predicted yield or $0.18 \%$ of PY\%AY. Thus, it is unlikely that the abbreviated General formula would apply in all situations, but there may be some situations, as in this review, where it would apply. It is interesting that the levels of ffpfWS in the 4 treatments of Neocleous et al. (2002) were estimated as $5.63,5.63,5.66$, and $5.66 \%$, respectively, midway in the range of this review noted above.

\section{Estimation of Moisture in Cheese}

The abbreviated General formula was rearranged to

$$
\begin{aligned}
\mathrm{M}= & {[\mathrm{Y} \times(1-\mathrm{SC})-\mathrm{FM} \times \mathrm{Kf}-1.0553} \\
& \times \mathrm{mp} \times \mathrm{KmpPr}] / 1.0603 \times \mathrm{Y},
\end{aligned}
$$

where $\mathrm{M}$ is a proportion and $\mathrm{Y}=$ yield of cheese, $\mathrm{kg} / 100$ $\mathrm{kg}$ of milk. This offered the possibility of estimation of $\mathrm{M}$ in vats producing large block cheese where cheese composition was not known, and only yield of cheese and fat and protein in milk were known. Table 12 used means of $\mathrm{Kf}$ and $\mathrm{KmpPr}$ of the 22 vats as constants as well as SC to predict M; the mean of predicted M was $0.22 \%$ higher than the measured $\mathrm{M}$, but the SD of the differences between estimated and measured $\mathrm{M}$ was $0.38 \%$.
The above formula for estimating $\mathrm{M}$ was adjusted using a SofC that was typical of these trials. The factors of M, FM, and mp were divided by 0.9976 . The mean of the differences between estimated predicted $\mathrm{M}$ and measured $\mathrm{M}$ was $0.00 \%$ but the SD was $0.38 \%$, the same as with no adjustment; this was higher than desirable. Use of measured Kf, KmpPr, and SofC for each vat reduced the SD to $0.01 \%$, indicating that varied $\mathrm{Kf}$ and $\mathrm{KmpPr}$ were chiefly responsible for the SD of $0.38 \%$, representing the differences between predicted and actual moistures in the 22 vats. However, this widened the parameters from using only yield and fat and $\mathrm{mp}$ in milk. No method was apparent for accounting for the effect of the Kf and KmpPr as constants as was done with adjustment using the SofC in estimation of adjusted yield (Table 10); an alternative would be to improve the uniformity of cheesemaking and reduce the variability of $\mathrm{Kf}$ and $\mathrm{KmpPr}$ from that achieved in this study.

It should be recognized that a form of this control of moisture using milk composition and yield of cheese seems to have been used in the Netherlands, as described by Lolkema (1994) and van den Berg et al. (1996). It is apparent that this requires close control of manufacturing procedures and uniform losses of fat and curd fines in the whey, giving uniform values of $\mathrm{Kf}$ and $\mathrm{KpmPr}$ in all vats.

\section{Normalization of Fat and Protein Recovery}

Normalization was mentioned earlier in Table 4 and Figure 4b. It has been used to assign the fat in milk proportionally to wheys and cheese so that the total recovery of fat was $100 \%$. This has been done in a number of studies, such as that of Neocleous et al. (2002). Normalization of the data in this experiment is illustrated in Table 13 for both fat and protein. The percentages of milk fat recovered in wheys and cheeses were divided by the total (as a fraction) recovered in each vat; the measured means were 8.85, 90.72, and $99.57 \%$, respectively. The mean normalized values were 8.89 and $91.11 \%$ for the wheys and cheese, respectively, and the totals were $100 \%$ in all vats. The SD for fat recovered in cheese decreased after normalization among vats to $0.66 \%$. The pattern was the same for normalization of the recovery of pc in milk as protein in cheese. As expected, mean percentages of normalized fat and protein in cheese increased to 35.53 and $24.26 \%$, respectively; mean recovery factors increased to 0.9111 and 0.9977 , respectively, and predicted yields (i.e., PY\%AY) increased to 99.83 and $99.63 \%$, respectively. However, an apparent problem exists in that the SD of the normalized PY\% AY values increased to 0.29 and $0.26 \%$, respectively, compared with $0.18 \%$ in 
Table 12. Estimation of moisture ${ }^{1}(\mathrm{M})$ in 22 vats of cheese using the abbreviated General formula and constant values of fat retention (Kf) and milk protein retention (KmpPr) in cheese ${ }^{2}$

\begin{tabular}{|c|c|c|}
\hline \multirow[b]{2}{*}{ Formula } & \multicolumn{2}{|c|}{ Actual M - estimated M } \\
\hline & $\begin{array}{c}\text { Mean } \\
\text { difference }(\%)\end{array}$ & $\begin{array}{c}\text { SD of } \\
\text { differences }(\%)\end{array}$ \\
\hline Unadjusted & -0.22 & 0.38 \\
\hline Adjusted with the mean SofC as a constant ${ }^{3}$ & 0.00 & 0.38 \\
\hline Adjusted with SofC estimated for each vat ${ }^{4}$ & 0.00 & 0.01 \\
\hline
\end{tabular}

${ }^{1}$ Values in the formula were in fractions. They were multiplied by 100 to give percentages in the table, the more common method of expression.

${ }^{2}$ The formula was rearranged to isolate moisture $(\mathrm{M})$ as a separate factor; the formula was used unadjusted and also adjusted for the sum of components (SofC). Rearranged abbreviated General formula: $\mathrm{M}=[\mathrm{Y} \times(1$ $-\mathrm{SC})-\mathrm{FM} \times \mathrm{Kf}-1.0553 \times \mathrm{mp} \times \mathrm{KmpPr}] / 1.0603 \times \mathrm{Y}$, where $\mathrm{Y}=$ yield of cheese; $\mathrm{SC}=$ cheese salt; $\mathrm{FM}=$ $\%$ fat in milk; and $\mathrm{mp}=$ milk protein.

${ }^{3}$ The fat and the protein in the $\mathrm{SofC}$ were estimated using constant values of $\mathrm{Kf}$ and $\mathrm{KmpPr}, 0.9076$ and 0.7488 , respectively; the mean SofC was 0.9976 .

${ }^{4}$ Fat and protein in SofC were estimated using values of $\mathrm{Kf}$ and $\mathrm{KmpPr}$ for each vat; the mean SofC was 0.9976 .

PY\%AY where normalization was not done; this led to the increased dispersion of the predicted yields with the normalized Barbano formula in Figure 4b and Table 4. We conclude that there is little value in normalization of predicted yields in view of the increased dispersion of predicted yields, the apparent uncertainty of predicted yields associated with variability in apparent SofC among vats, and the difficulty in finding only limited use for an unadjusted yield prediction.

\section{Possible Problems}

Surprisingly few problems were encountered in applying all 3 proteins (pc, cas, and $\mathrm{mp}$ ) in the formulas (only cas in the Barbano and Van Slyke formulas). One aspect is that of aberrant data, either with individual data or as systematic errors. It is obvious that such data would affect results with the formulas. This was not pursued further but the possibility of such problems should be recognized and possibly exploited in identifying problems in analysis and sampling.

\section{Sampling of Cheese and Milk, Interlaboratory Programs of Analysis, and Use of Control Samples}

Cheese plants need the most representative samples of cheese and milk and the best possible analyses of them. The importance of accurate sampling and analyses is illustrated here as follows. If one makes cheese at the target $\mathrm{M}$ but analysis overestimates $\mathrm{M}$ by $1 \%$ (e.g., analysis $=37 \%$, but $\mathrm{M}$ is really $36 \%$ ), yield would be $1.8 \%$ less than it should be (Emmons, 2000). Bradley and Vanderwarn (2001) described wide variations among laboratories in collaborative studies of cheese analysis, as did Emmons et al. (2001b).

Whether predictive formulas are used or not, it is recommended that cheese laboratories participate in an interlaboratory program of analysis of a number of cheese samples distributed periodically among participating labs (Emmons et al., 2000, 2001b). Means of results are shared as soon as possible so that a laboratory can see where it stands relative to other laboratories. Laboratories may also receive control samples for periodic analysis; that is, a number of subsamples of 1 or 2 of the above cheeses; these results are not shared. Such a program, the Canadian Cheese Analysis Program, has been used in Canada with Canadian Laboratory Services (92 Bentley St., Ottawa, ON, K4M 1J4, Canada) for about $15 \mathrm{yr}$.

The proper sampling of cheese is extremely important to give a sample representative of the vat of cheese. Particular care was taken in sampling cheese, the data of which were used in this review; 2 large subsamples were taken from each of the two 10-kg blocks in each vat. Sampling is a major problem in applying predictive yield formulas commercially. The International Dairy Federation (1995) developed Standard 50C:1995 for sampling cheeses of different sizes and shapes. In commercial plants, major difficulties of sampling large cheeses have occurred because of migration of $\mathrm{M}$ from warm to cool parts of the cheese during cooling. This has been described by Blattner et al. (1985), Reinbold and Ernstrom (1988), and Barbano (2001); each has made recommendations for sampling. Barbano (2001) stated that variations in $\mathrm{M}$ in large cheeses did not decrease with aging. The $\mathrm{M}$ moves in cheese, even 
Table 13. Normalization of fat and protein in 22 vats of cheese and its effect on recovery of fat (Kf) and paracasein $(\mathrm{KpcPr})$ and on predicted yield as a percentage of actual yield $(\mathrm{PY} \% \mathrm{AY})^{1}$

\begin{tabular}{|c|c|c|c|c|c|c|}
\hline \multirow[b]{2}{*}{ Component } & \multicolumn{3}{|c|}{ Percentage from milk in } & \multirow{2}{*}{$\begin{array}{l}\text { Percentage } \\
\text { in cheese }\end{array}$} & \multirow{2}{*}{$\begin{array}{l}\text { Recovery } \\
\text { factor }^{2}\end{array}$} & \multirow{2}{*}{$\begin{array}{c}\text { PY\%AY } \\
(\%)\end{array}$} \\
\hline & Wheys & Cheese & Total & & & \\
\hline Fat & & & & & Kf & \\
\hline Observed & 8.85 & 90.72 & 99.57 & 35.40 & 0.9076 & 99.61 \\
\hline SD & 0.66 & 0.78 & 0.46 & 0.71 & 0.0078 & 0.18 \\
\hline Normalized & 8.89 & 91.11 & 100.00 & 35.53 & 0.9111 & 99.83 \\
\hline SD & 0.66 & 0.66 & 0.00 & 0.73 & 0.0066 & 0.29 \\
\hline Protein & & & & & $\mathrm{KpcPr}$ & \\
\hline Observed & 25.04 & 74.87 & 99.92 & 24.25 & 0.9970 & 99.61 \\
\hline SD & 0.36 & 0.51 & 0.38 & 0.55 & 0.0049 & 0.18 \\
\hline Normalized & 25.06 & 74.94 & 100.00 & 24.26 & 0.9977 & 99.63 \\
\hline SD & 0.37 & 0.37 & 0.00 & 0.52 & 0.0029 & 0.26 \\
\hline
\end{tabular}

${ }^{1}$ Paracasein $(\mathrm{N} \times 6.38)$ was used with the General formula.

${ }^{2} \mathrm{Kf}=$ weight of cheese $\times$ fat in cheese $/$ fat in milk; $\mathrm{KpcPr}=$ weight of cheese $\times$ protein in cheese $/$ paracasein in milk.

in 100-g samples of ground cheese for analysis, when moved from refrigeration to room temperature (Emmons et al., 2001a); how much $\mathrm{M}$ moves in cheeses of intermediate sizes? One concludes that the question of how to reduce variability in composition in large blocks of cheese needs to be addressed, as well as improvement of sampling. The interdependence among sampling, analyses, and predictive yield formulas is abundantly evident.

\section{SUMMARY AND CONCLUSIONS}

Yields of cheese and analyses of components of milk, whey, and cheese on 22 vats were used to assess the efficacy of the General and Barbano formulas for prediction of cheese yield. It was startling that the SofC were less than $100 \%$ using an $\mathrm{N}$ conversion factor of 6.31 ; the mean was $99.51 \%(\mathrm{SD}=0.12 \%)$. The mean $\mathrm{SofC}$ using an $\mathrm{N}$ factor of 6.38 was $99.77 \%$. Importantly, the estimated SofC in cheese in several other studies were of the same order of magnitude, indicating that the values of SofC in this study were probably not unique.

Standard methods for the analyses of milk and dairy products are important for the functioning of the dairy industry. This review indicates that one should not assume that standard methods measure $100 \%$ of the components in question. The PY\% AY values were also lower than $100 \%$. The PY\%AY was closely related to the SofC of each of the 22 vats. We conclude that the unadjusted formula is not a precise predictor of yield, a disappointing revelation. However, the PY\%AY, calculated using an unadjusted formula, is likely to be useful in a control program for cheese and milk analyses.
It was possible to adjust the General formula so that the predicted yield equaled the actual yield. This was done for each vat by adding the components of cheese to give the SofC for each vat. Next, each measured component in the formula was divided by the SofC for that vat; the measured components were fat and $\mathrm{pc}$, cas, or mp in milk, and ffpfWS, M, and SC in cheese. The formula, adjusted for the SofC, gave the adjusted predicted yield. That adjusted yield equaled the actual yield.

It was possible to estimate the contents of fat, protein, ms, and ffpfWS in cheese using the predicting General and Barbano formulas (Table 5, Figure 5c). Those values and analyzed values for $\mathrm{M}$ and $\mathrm{SC}$ gave the SofC estimated using the formula. It should be noted that estimates for fat, protein, and whey solids required actual yields in their calculation, restricting this estimate to situations where actual yield is known. The adjusted formula is recommended for estimating target yields and CYE.

The cas and pc gave equal results with the General formula. It was unexpected that $\mathrm{mp}$ in the adjusted General formula gave the same predicted yields as cas and pc, suggesting that measurement of cas or pc in milk may not be necessary in all yield estimations. It is apparent that pc may be the component of choice in the future for yield applications; analysis of pc is easier than that of cas.

The use of constants for recovery of fat and protein in the adjusted General formula gave predicted yields equal to actual yields, indicating that analysis of cheese for fat and protein may not always be necessary for yield prediction. Adjustments of the General and Barbano formulas seemed to work equally well using cas 
and mp. However, the unadjusted Barbano formula gave skewed estimates of protein in cheese.

Most of the foregoing calculations used measurements for each of the components of cheese in the 22 vats. Constants were used successfully for $h$ and Kms. Unexpectedly, a constant for ffpfWS could be used with this set of data. This enabled a simplification of the General formula to $\mathrm{Y}=(\mathrm{FM} \times \mathrm{Kf}+1.056 \times \mathrm{pc} \times$ $\mathrm{KpcPr}) /(1-\mathrm{SC}-1.06 \times \mathrm{M})$.

Normalization of the fat and protein contents of cheese resulted in mean values for yields predicted with unadjusted formulas that were closer to actual yields. However, the SD of PY\% AY values was greater and, consequently, normalization is not recommended.

The interdependence of predictive yield formulas and accuracy of sampling and analysis of cheese is emphasized. It is encouraging that these manipulations were successful with this set of data. The question remains whether this occurs with a broad range of other data.

\section{ACKNOWLEDGMENTS}

The assistance of Carol Campbell, Ralph Cooligan, Harold Daley, Cheryl Defelice, Claudine Dubé, Bruce Dunlop, and Christina Nadeau in this work is gratefully acknowledged, as are discussions and contributions of W. V. Price, C. A. Ernstrom, D. M. Barbano, T. Callanan, K. Johnston, C. Lacroix, H. Lolkema, F. Rentsch, D. St. Gelais, R. Sellars, R. Sieber, M. A. J. S. van Boekel, G. van den Berg, and many others at various times and places. Acknowledged also are the encouragement by C. L. Hicks to prepare this commentary and the provision of data for acids and sugars by W. J. Mullin and for mineral analyses by M. Ihnat.

\section{REFERENCES}

Babcock, S. M. 1895. Experiments in the manufacture of cheese. Eleventh Ann. Rep. Agric. Exp. Stn., Univ. Wisconsin for year ending June 30, 1894. University of Wisconsin, Madison.

Barbano, D. M. 1984. Mozzarella cheese composition, yield, and how composition control influences profitability. Pages 1-13 in Proc. 21st Ann. Marschall Invitational Italian Cheese Seminar, Madison, WI.

Barbano, D. M. 1994. A spreadsheet system for evaluation and improvement of cheese yield performance. Pages 339-344 in Cheese Yield and Factors Affecting Its Control. Proc. IDF Seminar, Cork, Ireland.

Barbano, D. M. 2000. Chapter 7 in Practical Guide for Control of Cheese Yield. Special Issue No. 0001. International Dairy Fed., Brussels, Belgium.

Barbano, D. M. 1996. Mozzarella cheese yield: Factors to consider. Pages 29-38 in Proc. Wisconsin Cheese Makers Mtg., Ctr. Dairy Res., Univ. Wisconsin, Madison.

Barbano, D. M. 2001. Moisture nonuniformity and sampling errors in large Cheddar cheese blocks. J. AOAC Int. 84:613-619.

Barbano, D. M., and J. W. Sherbon. 1984. Cheddar cheese yields in New York. J. Dairy Sci. 67:1873-1883.
Blattner, T. M., N. F. Olson, and D. W. Wichern. 1985. Sampling barrel cheese for moisture analysis: Comparison of methods . J. AOAC 68:718-721.

Bradley, R. L. Jr., and M. A. Vanderwarn. 2001. Determination of moisture in cheese and cheese products. J. AOAC Int. 84:570592.

de Koning, P. J., R. de Boer, P. Both, and D. F. C. Nooy. 1981. Comparison of proteolysis in a low-fat semi-hard type of cheese manufactured by standard and ultrafiltration techniques. Neth. Milk Dairy J. 35:35-46.

Emmons, D. B. 1996. Modification of cheese yield formula of Van Slyke and Publow . J. Dairy Sci. 79(Suppl. 1):103. (Abstr.)

Emmons, D. B. 2000. Sampling and analysis. Chapter 10 in Practical Guide for Control of Cheese Yield. Special Issue No. 0001. Pub. International Dairy Fed., Brussels, Belgium.

Emmons, D. B., R. L. Bradley Jr., C. Campbell, and P. Sauvé. 2001a. Movement of moisture in refrigerated cheese samples transferred to room temperature. J. AOAC Int. 84:620-622.

Emmons, D. B., R. L. Bradley Jr., J. P. Sauvé, C. Campbell, C. Lacroix, and S. A. Jiminez-Marquez. 2001b. Variations of moisture measurements in cheese. J. AOAC Int. 84:593-604.

Emmons, D. B., C. Dubé, and H. W. Modler. 2003. Transfer of protein from milk to cheese. J. Dairy Sci. 86:469-485.

Emmons, D. B., C. A. Ernstrom, C. Lacroix, and P. Sauvé. 1993. Further considerations in formulas for predicting yield from the composition of milk. J. Dairy Sci. 76:914-920.

Emmons, D. B., C. A. Ernstrom, C. Lacroix, and P. Verret. 1990. Predictive yield formulas for yield of cheese. J. Dairy Sci. 73:13651394.

Emmons, D. B., O. Leray, and P. J. Sauvé. 2000. Proficiency testing for control of analysis. Chapter 11 in Practical Guide for Control of Cheese Yield. Special Issue No. 0001. Pub. International Dairy Fed., Brussels, Belgium.

Emmons, D. B., H. W. Modler, G. Butler, and M. Wolynetz. 1997. Retention of skimmilk starter proteins in cheese and their effect on yield. J. Dairy Sci. 80(Suppl.1):98. (Abstr.)

Ernstrom, C. A., R. J. Brown, H. Abu-tarboush, and G. Majeed. 1981. The value of milk used for Mozzarella and Swiss cheese. Jersey J. 28(April):49-51.

Fenelon, M. A., and T. P. Guinee. 1999. The effect of milk fat on Cheddar cheese yield and prediction, using modifications of the Van Slyke cheese yield formula. J. Dairy Sci. 82:2287-2299.

Guinee, T. P., E. O. Mulholland, J. Kelly, and D. J. O. Callaghan. 2007. Effect of protein-to-fat ratio of milk on the composition, manufacturing efficiency, and yield of Cheddar cheese. J. Dairy Sci. 90:110-123.

International Dairy Federation (IDF). 1986. Determination of nitrogen content (Kjeldahl method) and calculation of crude protein content. Standard 20A. International Dairy Fed., Brussels, Belgium.

International Dairy Federation (IDF). 1993. Factors Affecting the Yield of Cheese. Special Issue No. 9301. International Dairy Fed., Brussels, Belgium.

International Dairy Federation (IDF). 1994. Cheese Yield and Factors Affecting Its Control. Proc. of IDF Seminar, Cork, Ireland. International Dairy Fed., Brussels, Belgium.

International Dairy Federation (IDF). 1995. Milk and Dairy Products. Guidance on Sampling. Standard 50C. International Dairy Federation, Brussels, Belgium.

International Dairy Federation (IDF). 2000. Practical guide for Control of Cheese Yield. Special Issue No. 0001. International Dairy Fed., Brussels, Belgium.

Jenness, R., and S. Patton. 1959. Principles of Dairy Chemistry. John Wiley and Sons Inc., New York, NY.

Karman, A. H., M. A. J. S. van Boekel, and A. P. Arentsen-Stasse. 1987. A simple and rapid method to determine the casein content of milk by infrared spectrophotometry. Neth. Milk Dairy J. 41:175-187.

Lo, C. G., and E. D. Bastian. 1998. Incorporation of native and denatured whey proteins into cheese curd for manufacture of reducedfat, Havarti-type cheese. J. Dairy Sci. 81:16-24. 
Lolkema, H. 1994. Cheese yield used as an instrument for process control-Experience in Friesland, the Netherlands. Chapter 14 in Factors Affecting the Yield of Cheese. Special Issue No. 9301. International Dairy Fed., Brussels, Belgium.

Maubois, J.-L., and G. Mocquot. 1971. L'appréciation des rendements en fromagerie. Lait 507:417.

Mullin, W. J., and D. B. Emmons. 1997. Determination of organic acids and sugars in cheese, milk and whey by high performance liquid chromatography. Food Res. Int. 30:147-151.

Neocleous, M., D. M. Barbano, and M. A. Rudan. 2002. Impact of low concentration factor microfiltration on milk component recovery and Cheddar cheese yield. J. Dairy Sci. 85:2415-2424.

O'Keefe, A. M., P. F. Fox, and C. Daly. 1978. Proteolysis in Cheddar cheese: Role of coagulant and starter bacteria. J. Dairy Res. 45:465-477.

Olling, Ch. C. J. 1963. Composition of Friesian whey. Neth. Milk Dairy J. 17:176-184.

Posthumus, G., C. J. Booy, and C. J. Klijn. 1964. The relation between the protein content of milk and cheese yield. Neth. Milk Dairy J. 18:155-164.

Reinbold, R. S., and C. A. Ernstrom. 1988. Effect of non-uniform cooling on moisture, salt and $\mathrm{pH}$ distribution in 290-kilogram blocks of stirred-curd Cheddar cheese. J. Dairy Sci. 71:1499-1506.

van Boekel, M. A. J. S. 1994. Transfer of milk components to cheese: scientific considerations. In Cheese Yield and Factors Affecting its Control, IDF Seminar, Cork, Ireland, 1993. Special Issue No. 9402. International Dairy Fed., Brussels, Belgium.

van Boekel, M. A. J. S., and B. Ribadeau-Dumas. 1987. Addendum to the evaluation of the Kjeldahl factor for conversion of the nitrogen content of milk and milk products to protein content. Neth. Milk Dairy J. 41:281-284.

van den Berg, M. G., G. van den Berg, and M. A. J. S. van Boekel. 1996. Mass transfer processes involved in Gouda cheese manufacture, in relation to casein and yield. Neth. Milk Dairy J. 50:501540.

Van Slyke, L. L., and W. V. Price. 1949. Cheese. Orange Judd Co. Inc., New York, NY.

Van Slyke, L. L., and C. A. Publow. 1910. The Science and Practice of Cheese-Making. Orange Judd Co. Inc., New York, NY.

\section{APPENDIX}

The following is an example for the calculation of adjusted target yield and cheese yield efficiency using the General formula, where neither fat nor protein content of cheese is known, and where the content of neither pc nor cas in milk is known, only total protein. The example is vat 1 in the experiment. Table A1 gives the parameters of the General formula.

Table A2 gives the parameters for vat 1 .
Table A1. Parameters of the General formula

\begin{tabular}{|c|c|c|}
\hline Constant $^{1}$ & Selected & Measured \\
\hline Kf & 0.91 & 0.921 \\
\hline $\mathrm{KmpPr}^{2}$ & 0.75 & 0.749 \\
\hline Kms & 0.08 & 0.0812 \\
\hline $\operatorname{sef}(h)$ & 0.41 & 0.382 \\
\hline
\end{tabular}

${ }^{1} \mathrm{Kf}=$ recovery of milk fat as cheese $(\mathrm{ch})=$ weight $\mathrm{ch} \times$ fat $\mathrm{ch} /$ weight milk $\times$ fat in milk; KmpPr $=$ recovery factor for milk protein $(\mathrm{mp})$ in cheese; $\mathrm{Kms}=1+$ ratio of milk salts $(\mathrm{ms})$ to protein in cheese; sef $=$ solute-exclusion factor, also known as $h$.

${ }^{2}$ If true milk protein was used, the $\mathrm{KmpPr}$ constant would likely be near 0.80 instead of 0.75

Table A2. Parameters for vat 1

\begin{tabular}{lc}
\hline Parameter & Value $^{1}$ \\
\hline Fat in milk (\%) & 3.77 \\
Total protein in milk (\%) & 3.09 \\
Moisture in cheese (\%) & $35.30(0.353)$ \\
Salt in cheese (\%) & $1.43(0.0143)$ \\
Fat-free, protein-free solids in whey (ffpfWS) (\%) & $5.70(0.057)$ \\
Weight of cheese (kg/100 kg of milk) & 9.71 \\
\hline
\end{tabular}

${ }^{1}$ Values in parentheses the contents of those components in cheese as proportions and are used as such in the various calculations.

Step 1 is to calculate the unadjusted composition of cheese (see Table 4 and text) using the General formula. Table A3 gives the calculations used.

Step 2 involves calculation of target yield using the adjusted General formula. The targets are 37\% moisture and $1.7 \%$ salt. For calculation of adjusted yield, use the working form of the General formula, dividing the fat in milk, protein in milk, $\mathrm{M}$ in cheese, SC, and ffpfWS by the SofC (0.9939). The adjusted target yield is $10.056 \mathrm{~kg}$.

Step 3 involves calculation of cheese yield efficiency (CYE):

CYE $=$ actual yield $\times 100 /$ adjusted target yield $=$

$$
9.71 \times 100 / 10.056=96.6 \% .
$$

Table A3. Calculation of unadjusted composition and sum of components (SofC)

\begin{tabular}{ll}
\hline Composition and formula & Value $^{1}$ \\
\hline Fat in cheese $(3.77 \times 0.91 / 9.71)$ & 0.3533 \\
Protein in cheese $(3.09 \times 0.75 / 9.71)$ & 0.2387 \\
Measured moisture $(\mathrm{M})$ & 0.3530 \\
Measured cheese salt $(\mathrm{SC})$ & 0.0143 \\
Milk salts associated with cheese protein $(0.08 \times 0.2387)$ & 0.0191 \\
ffpfWS $^{1}[0.353 \times 0.057 /(1-0.057)-0.41 \times 3.09 \times 0.75 \times 0.057 /(1-0.057) / 9.71]$ & 0.0154 \\
Total $($ SofC $)$ & 0.9939 \\
\hline
\end{tabular}

\footnotetext{
${ }^{1}$ Values are proportions in cheese, not percentages.

${ }^{2} \mathrm{ffpfWS}=$ fat-free, protein-free whey solids.
} 